\title{
Utilizing Photoionization Efficiency Spectroscopy and Density Functional Theory to Investigate Charge Transfer Interactions in $\mathrm{AuCe}_{3} \mathrm{O}_{n}$ Clusters
}

\author{
Robert A. Hardy, Aidan M. Karayilan and Gregory F. Metha* \\ Department of Chemistry, The University of Adelaide, South Australia 5005, Australia
}

\section{Supporting Information}

This document contains the following supporting information figures:

Figure S1 and S2: Photoionization mass spectra for $\mathrm{AuCe}_{m} \mathrm{O}_{n}$ and $\mathrm{Ce}_{m} \mathrm{O}_{n}$ clusters, respectively.

Figures S3-S14: PIE spectra and DFT-calculated structures for $\mathrm{Ce}_{3} \mathrm{O}_{n}$ and $\mathrm{AuCe}_{3} \mathrm{O}_{n}$ clusters.

Figure S15: Calculated $\mathrm{Au}, \mathrm{O}$ and $\mathrm{CeO}_{2}$ bonding energies for $\mathrm{Ce}_{3} \mathrm{O}_{n}$ and $\mathrm{AuCe}_{3} \mathrm{O}_{n}$ clusters.

Figures S16-S29: Calculated neutral and cationic $\mathrm{Ce}_{3} \mathrm{O}_{n}$ and $\mathrm{AuCe}_{3} \mathrm{O}_{n}$ geometries showing bond lengths and structure point groups. 


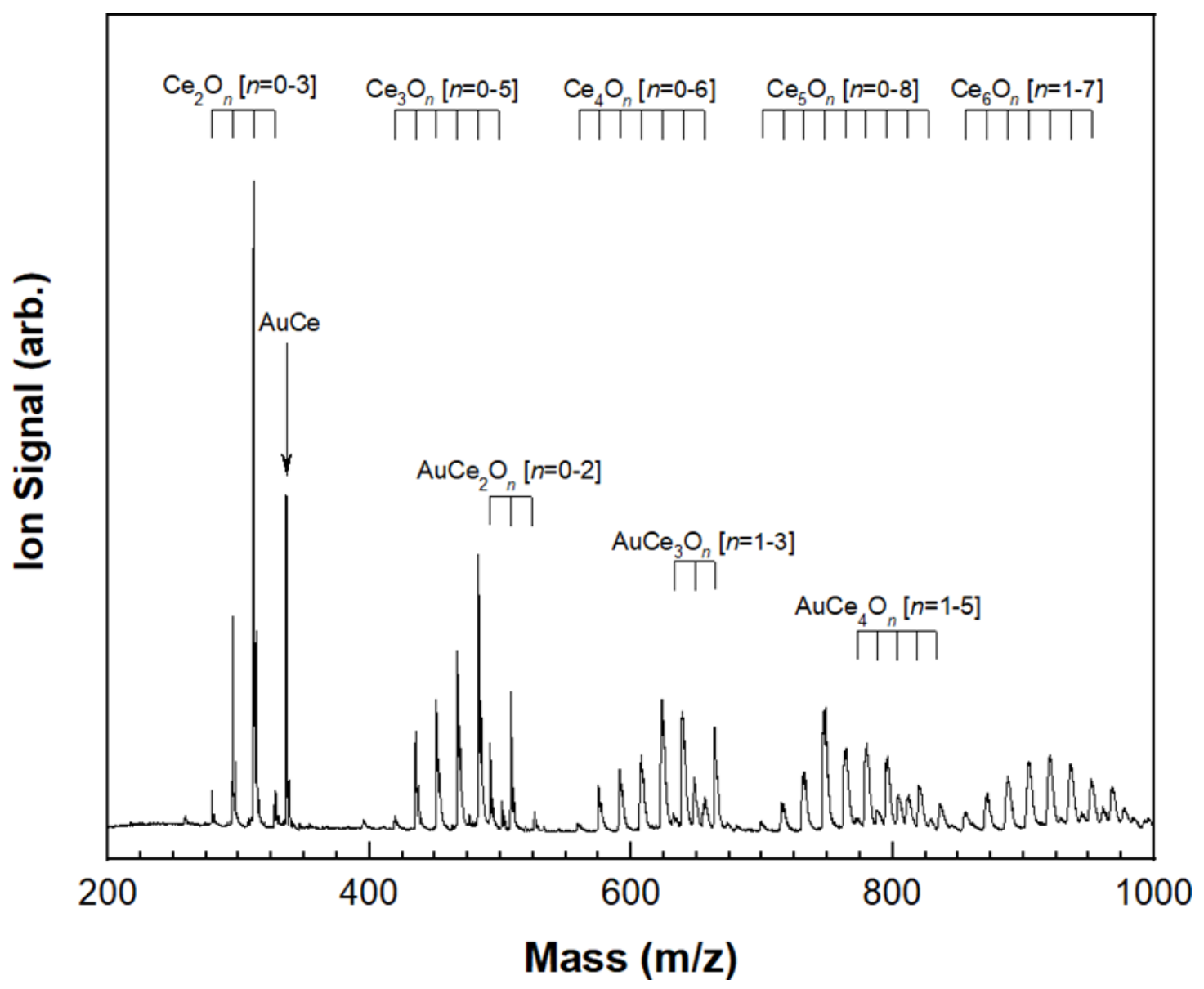

Figure S1: Typical mass spectrum of $\mathrm{AuCe}_{m} \mathrm{O}_{n}{ }^{+}$clusters recorded following photoionization at $213 \mathrm{~nm}(5.82 \mathrm{eV})$. The $\mathrm{AuCe}_{m} \mathrm{O}_{n}$ and $\mathrm{Ce}_{m} \mathrm{O}_{n}$ ion peaks are labelled with ladders. 


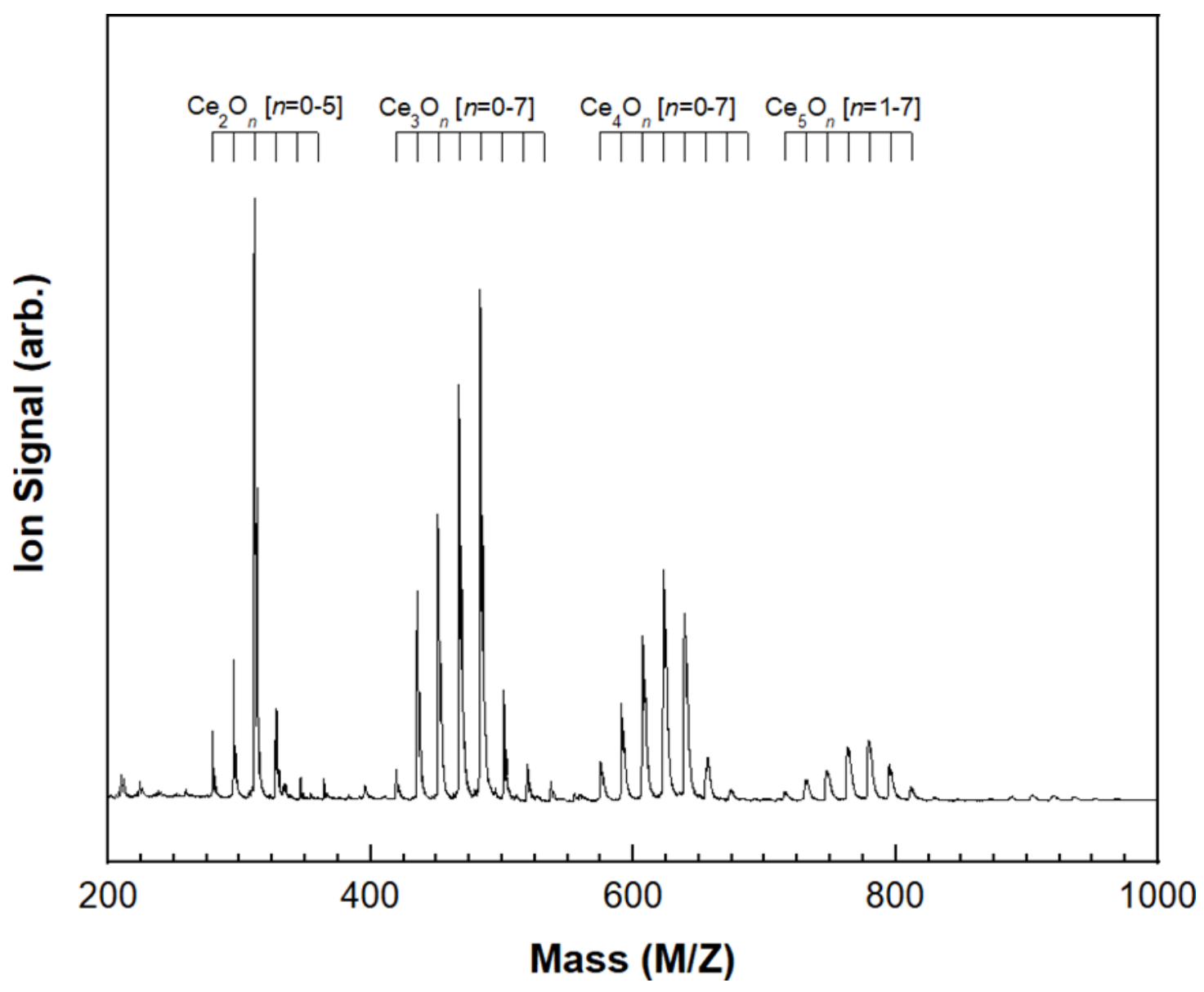

Figure S2: Mass spectrum of $\mathrm{Ce}_{m} \mathrm{O}_{n}{ }^{+}$clusters recorded following photoionization at $213 \mathrm{~nm}(5.82 \mathrm{eV})$. The $\mathrm{Ce}_{m} \mathrm{O}_{n}$ ion peaks are labelled with ladders. 


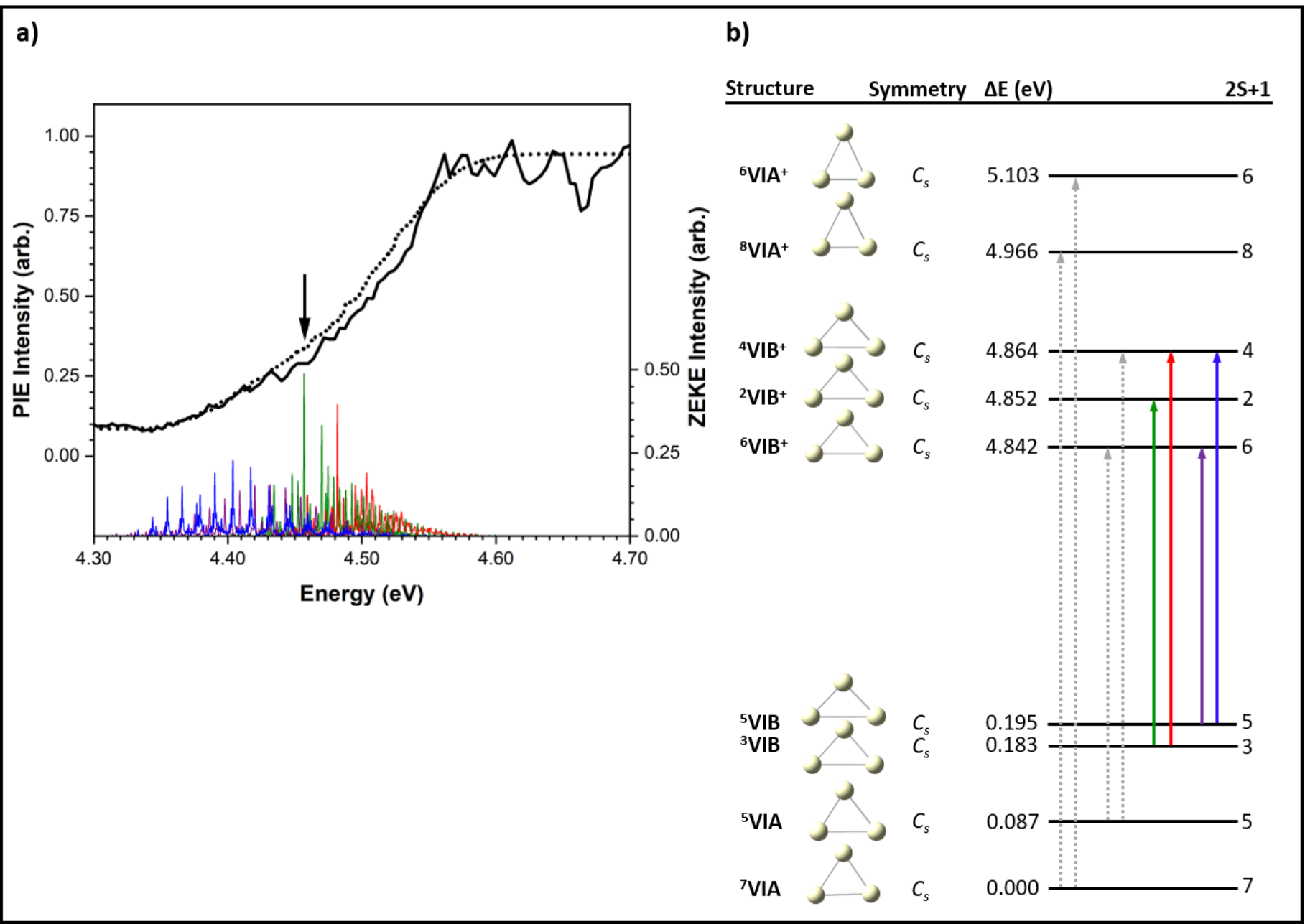

Figure S3: a). PIE spectrum for the $\mathrm{Cе}_{3}$ cluster. Experimentally recorded and calculated PIE spectra are shown as solid and dotted black lines, respectively. Calculated ZEKE spectra for underlying ionization transitions are shown below the PIE spectra in green, red purple and blue. The downward arrow indicates the adiabatic IE, the lowest energy origin transition. b). Calculated $\mathrm{Ce}_{3}$ structures and ionization processes. Ionization transitions are shown as coloured arrows which correspond to their respective ZEKE spectra. Ionization processes not considered to contribute to the PIE spectrum - due to weak FC overlap - are shown as dotted grey arrows. 


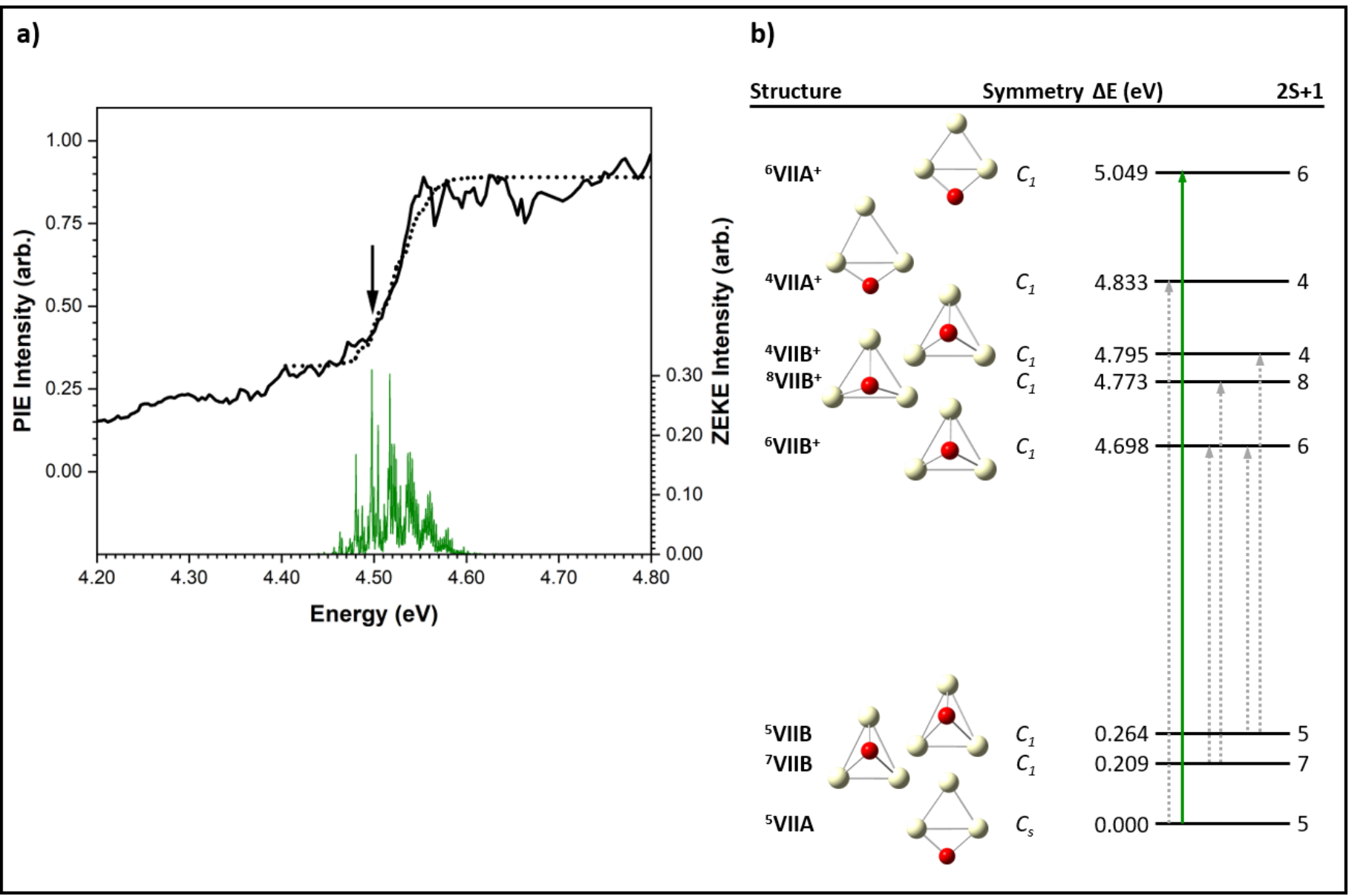

Figure S4: a). PIE spectrum for the $\mathrm{Ce}_{3} \mathrm{O}$ cluster. Experimentally recorded and calculated PIE spectra are shown as solid and dotted black lines, respectively. The calculated ZEKE spectrum for the underlying ionization transitions is shown below the PIE spectrum in green. The downward arrow indicates the adiabatic IE, the lowest energy origin transition. b). Calculated $\mathrm{Ce}_{3} \mathrm{O}$ structures ( $\mathrm{Ce}$ is white and $\mathrm{O}$ is red) and ionization processes. Ionization transitions are shown as coloured arrows which correspond to their respective ZEKE spectra. Ionization processes not considered to contribute to the PIE spectrum - due to weak FC overlap - are shown as dotted grey arrows. 


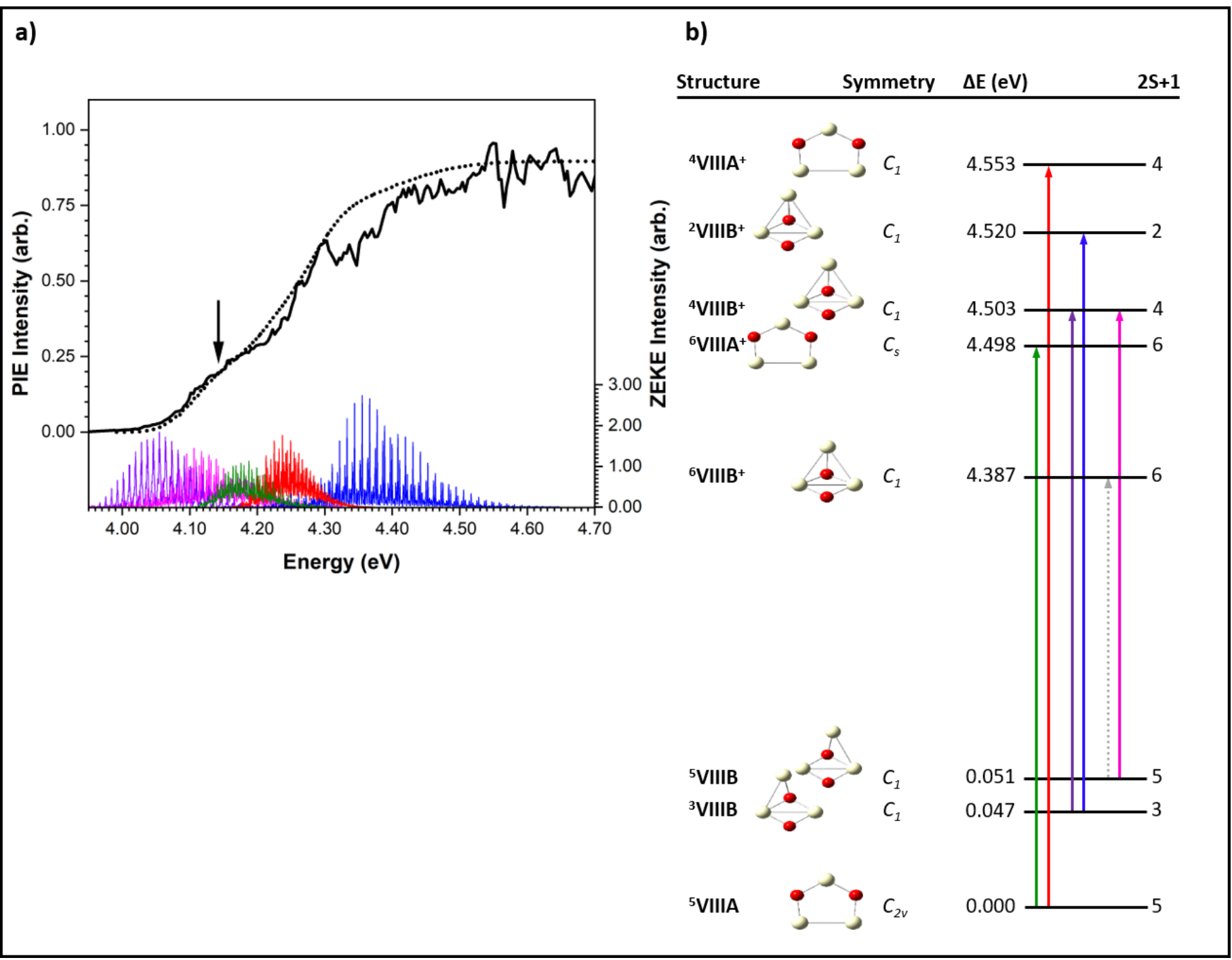

Figure S5: a). PIE spectrum for the $\mathrm{Ce}_{3} \mathrm{O}_{2}$ cluster. Experimentally recorded and calculated PIE spectra are shown as solid and dotted black lines, respectively. Calculated ZEKE spectra for underlying ionization transitions are shown below the PIE spectrum in green, red, violet, blue and magenta. The downward arrow indicates the adiabatic IE, the lowest energy origin transition. b). Calculated $\mathrm{Ce}_{3} \mathrm{O}_{3}$ structures ( $\mathrm{Ce}$ is white and $\mathrm{O}$ is red) and ionization processes. Ionization transitions are shown as coloured arrows which correspond to their respective ZEKE spectra. Ionization processes not considered to contribute to the PIE spectrum - due to weak FC overlap - are shown as dotted grey arrows. 


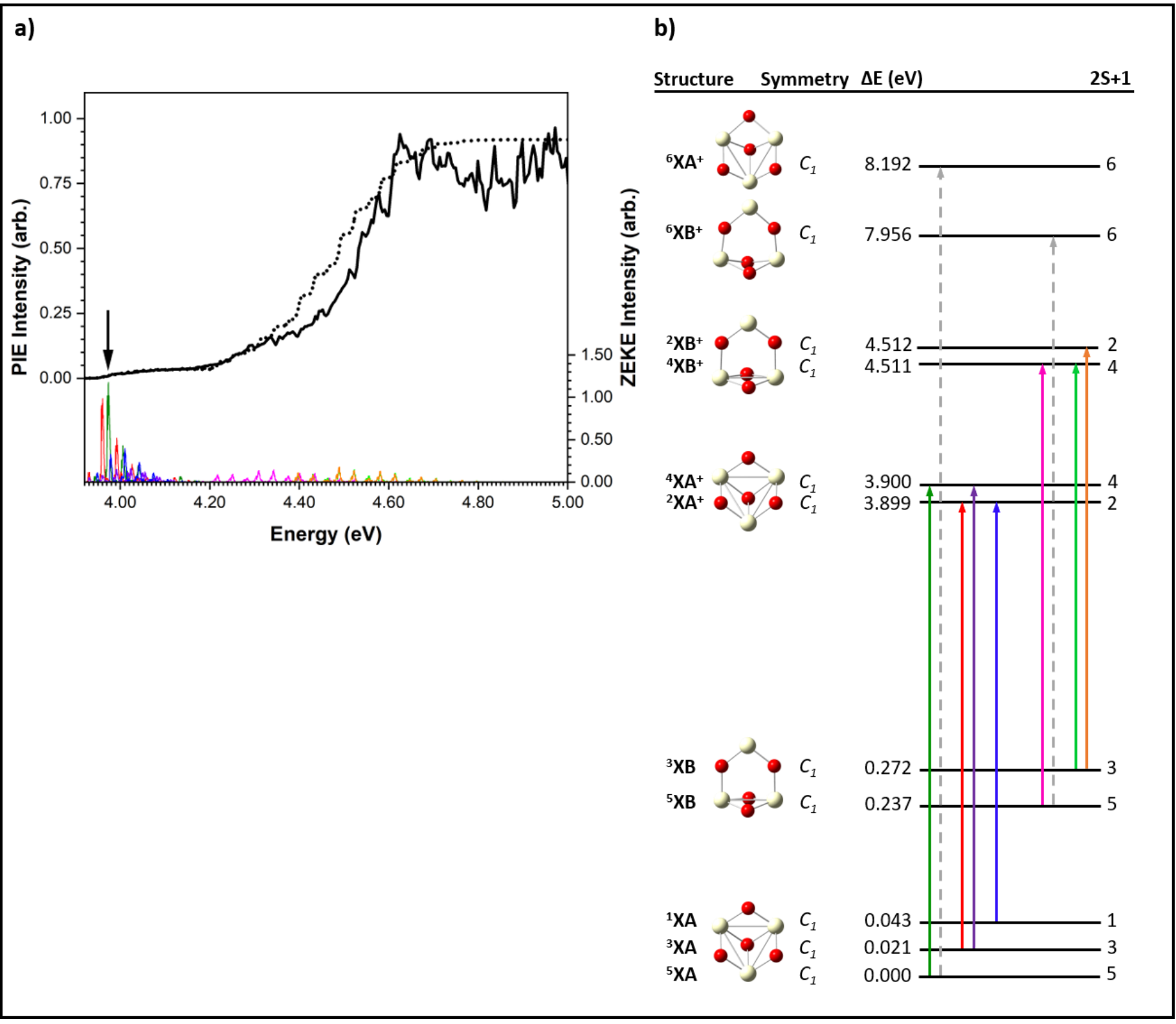

Figure S6: a). PIE spectrum for the $\mathrm{Ce}_{3} \mathrm{O}_{4}$ cluster. Experimentally recorded and calculated PIE spectra are shown as solid and dotted black lines, respectively. Calculated ZEKE spectra for the underlying ionization transitions are shown below the PIE spectrum in green, red, violet, blue, magenta, lime and orange. The downward arrow indicates the adiabatic IE, the lowest energy origin transition. b). Calculated $\mathrm{Ce}_{3} \mathrm{O}_{4}$ structures ( $\mathrm{Ce}$ is white and $\mathrm{O}$ is red) and ionization processes. Ionization transitions are shown as coloured arrows which correspond to their respective ZEKE spectra. Ionization processes not considered to contribute to the PIE spectrum - due to high ionization energies are shown as dashed grey arrows. 


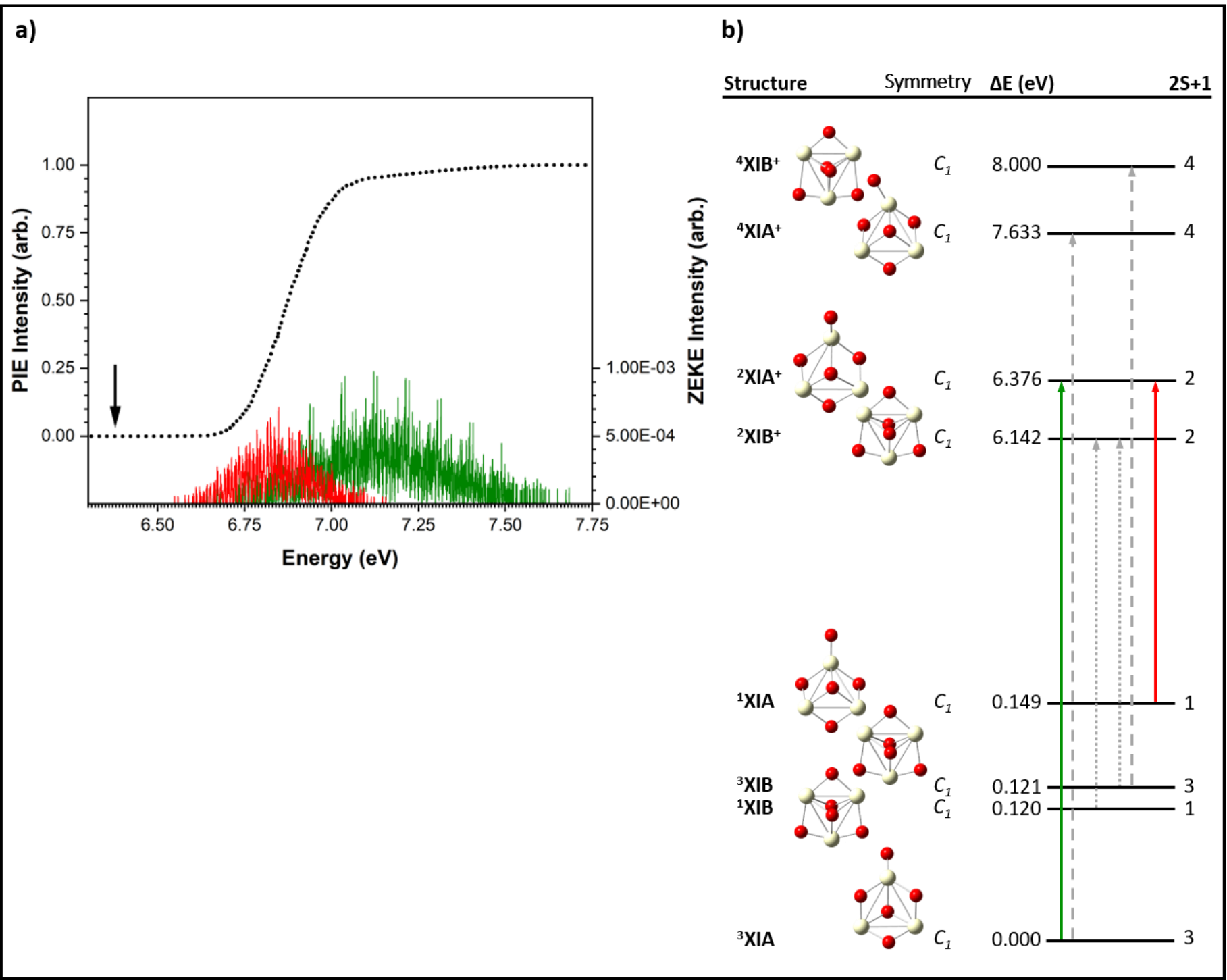

Figure S7: a). PIE spectrum for the $\mathrm{Ce}_{3} \mathrm{O}_{5}$ cluster. The calculated PIE spectrum is shown as a dotted black line.

Calculated ZEKE spectra for the underlying ionization transitions are shown below the PIE spectrum in green and red. The downward arrow indicates the calculated adiabatic IE, the lowest energy origin transition. b). Calculated $\mathrm{Ce}_{3} \mathrm{O}_{5}$ structures ( $\mathrm{Ce}$ is white and $\mathrm{O}$ is red) and ionization processes. Ionization transitions are shown as coloured arrows which correspond to their respective ZEKE spectra. Ionization processes not considered to contribute to the PIE spectrum - due to high ionization energies and weak FC overlap - are shown as dashed grey arrows and dotted grey arrows, respectively. 


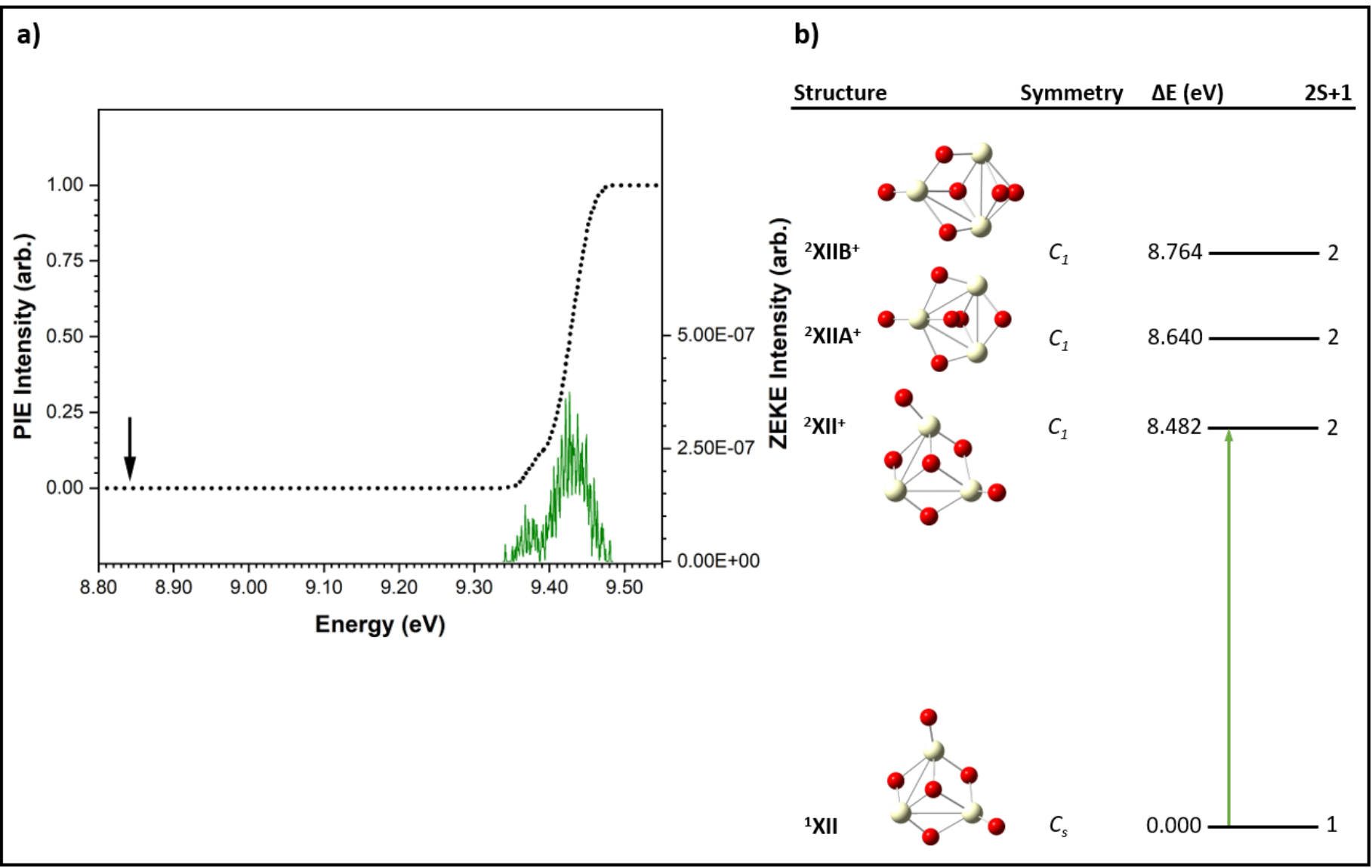

Figure S8: a). PIE spectrum for the $\mathrm{Ce}_{3} \mathrm{O}_{6}$ cluster. The calculated PIE spectrum is shown as a dotted black line. The calculated ZEKE spectrum for the underlying ionization transition is shown below the PIE spectrum in green. The downward arrow indicates the calculated adiabatic IE, the lowest energy origin transition. b). Calculated $\mathrm{Ce}_{3} \mathrm{O}_{6}$ structures ( $\mathrm{Ce}$ is white and $\mathrm{O}$ is red) and ionization processes. Ionization transitions are shown as coloured arrows which correspond to their respective ZEKE spectra. The ${ }^{2} \mathbf{X I I A}^{+}$and ${ }^{2} \mathbf{X I I B}^{+}$structures are shown for completeness only. 


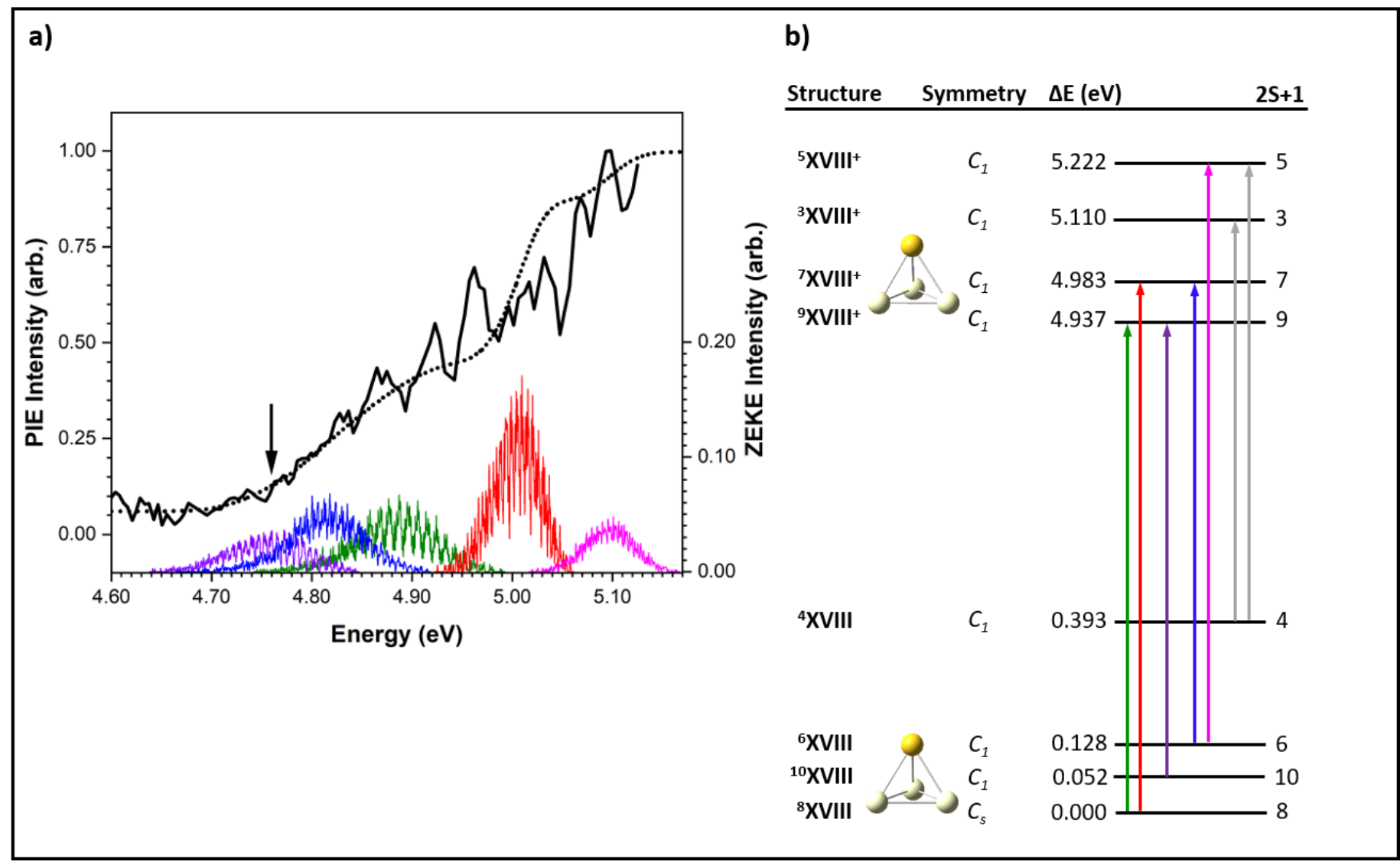

Figure S9: a). PIE spectrum for the $\mathrm{AuCe}_{3}$ cluster. Experimentally recorded and calculated PIE spectra are shown as solid and dotted black lines, respectively. Calculated ZEKE spectra for underlying ionization transitions are shown below the PIE spectra in green, red, purple, blue and magenta. The downward arrow indicates the adiabatic IE, the lowest energy origin transition. b). Calculated AuCez structures ( $\mathrm{Au}$ is yellow and $\mathrm{Ce}$ is white) and ionization processes. Ionization transitions are shown as coloured arrows which correspond to their respective ZEKE spectra. Ionization processes not considered to contribute to the PIE spectrum - due to energetically unfavourable neutral species - are shown as solid grey arrows. 


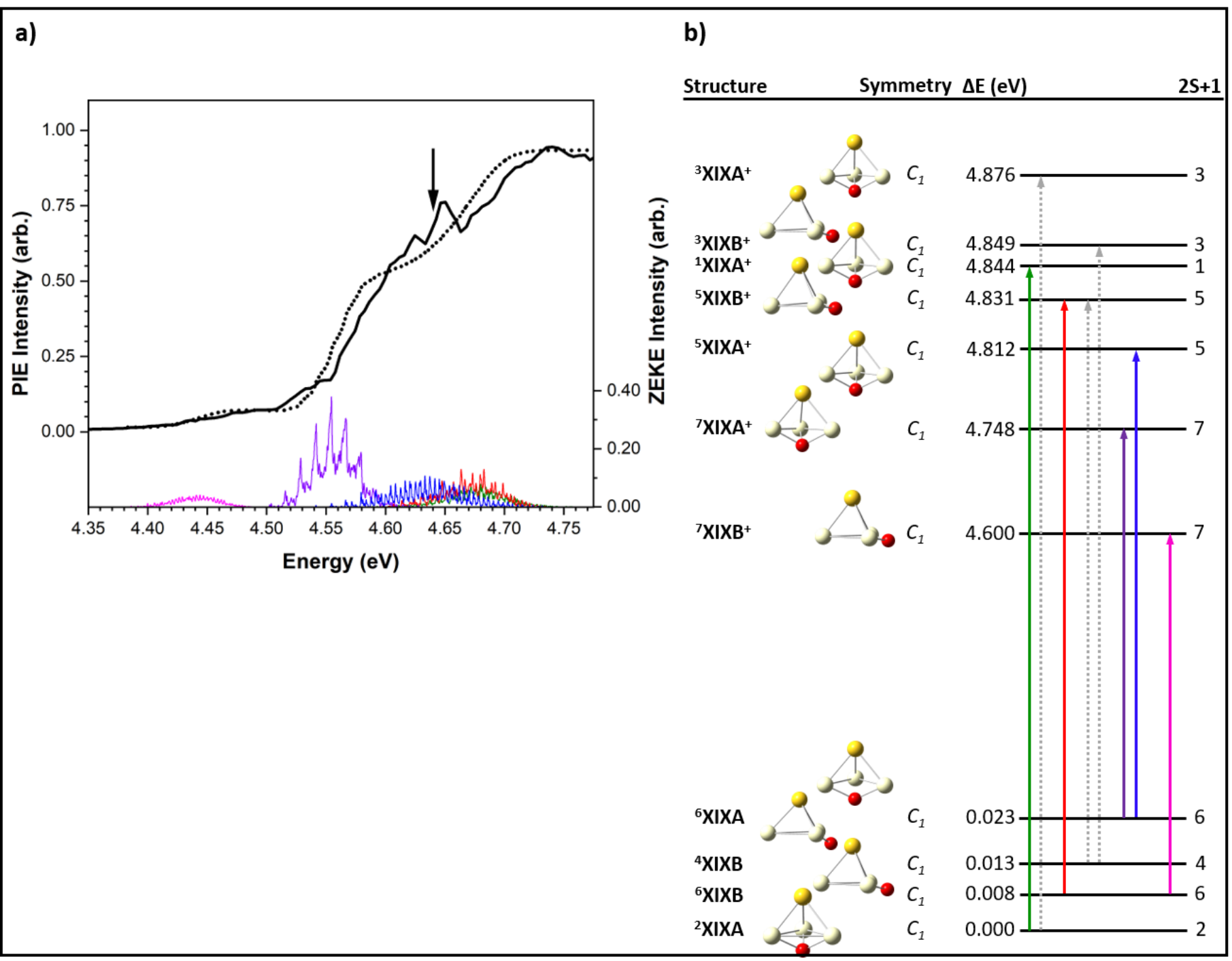

Figure S10: a). PIE spectrum for the $\mathrm{AuCe}_{3} \mathrm{O}$ cluster. Experimentally recorded and calculated PIE spectra are shown as solid and dotted black lines, respectively. Calculated ZEKE spectra for underlying ionization transitions are shown below the PIE spectra in green, red, violet, blue and magenta. The downward arrow indicates the adiabatic IE, the lowest energy origin transition. b). Calculated $\mathrm{AuCe}_{3} \mathrm{O}$ structures ( $\mathrm{Au}$ is yellow, $\mathrm{Ce}$ is white and $\mathrm{O}$ is red) and ionization processes. Ionization transitions are shown as coloured arrows which correspond to their respective ZEKE spectra. Ionization processes not considered to contribute to the PIE spectrum - due to weak FC overlap - are shown as dotted grey arrows. 


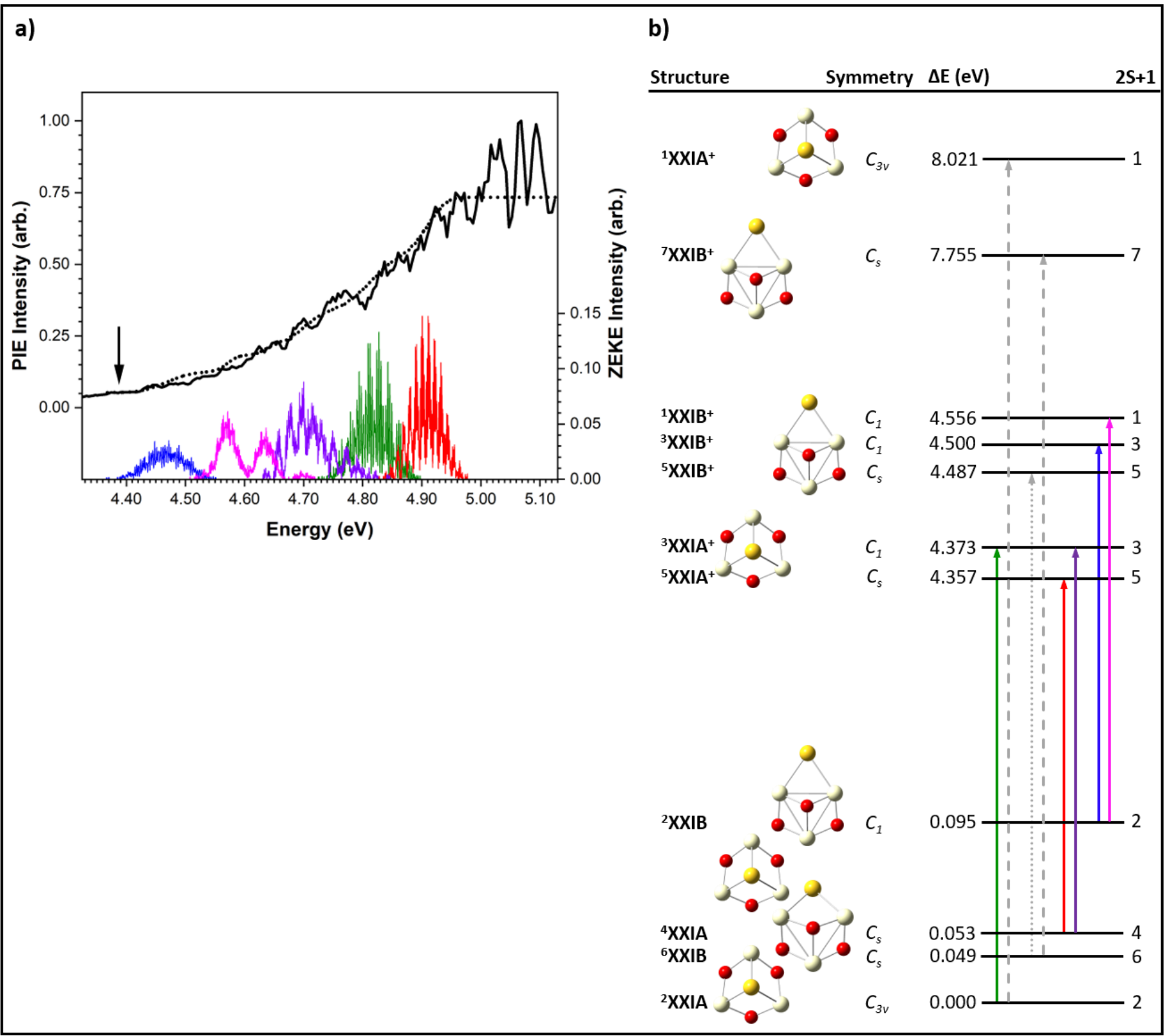

Figure S11: a). PIE spectrum for the $\mathrm{AuCe}_{3} \mathrm{O}_{3}$ cluster. Experimentally recorded and calculated PIE spectra are shown as solid and dotted black lines, respectively. Calculated ZEKE spectra for underlying ionization transitions are shown below the PIE spectra in green, red, violet, blue and magenta. The downward arrow indicates the adiabatic IE, the lowest energy origin transition. b). Calculated $\mathrm{AuCe}_{3} \mathrm{O}_{3}$ structures ( $\mathrm{Au}$ is yellow, $\mathrm{Ce}$ is white and $\mathrm{O}$ is red) and ionization processes. Ionization transitions are shown as coloured arrows which correspond to their respective ZEKE spectra. Ionization processes not considered to contribute to the PIE spectrum - due to high ionization energies and weak FC overlap - are shown as dashed grey arrows and dotted grey arrows, respectively. 


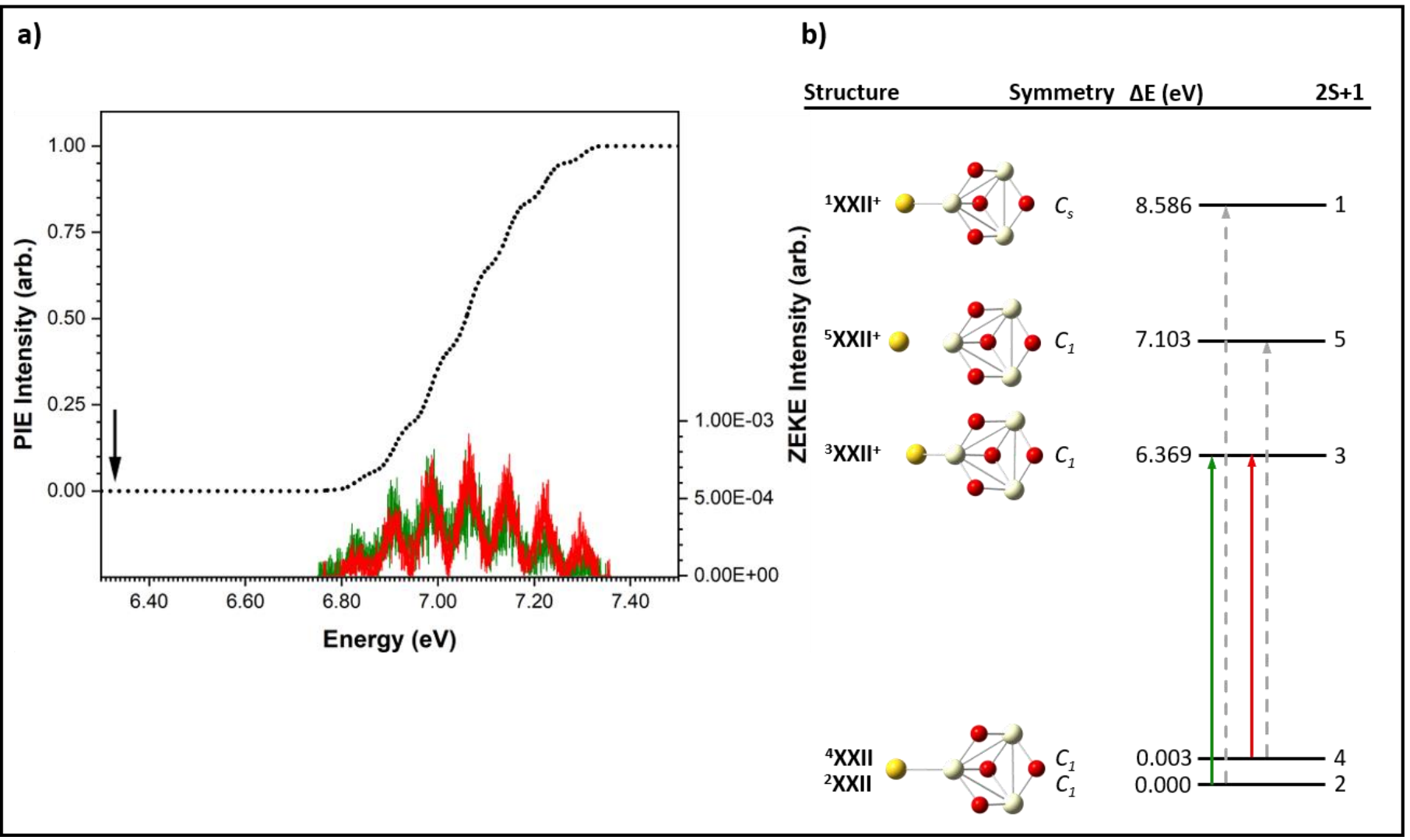

Figure S12: a). PIE spectrum for the $\mathrm{AuCe}_{3} \mathrm{O}_{4}$ cluster. The calculated PIE spectrum is shown as a dotted black line. Calculated ZEKE spectra for underlying ionization transitions are shown below the PIE spectra in green and red. The downward arrow indicates the calculated adiabatic IE, the lowest energy origin transition. b). Calculated $\mathrm{AuCe}_{3} \mathrm{O}_{4}$ structures ( $\mathrm{Au}$ is yellow, $\mathrm{Ce}$ is white and $\mathrm{O}$ is red) and ionization processes. Ionization transitions are shown as coloured arrows which correspond to their respective ZEKE spectra. Ionization processes not considered to contribute to the PIE spectrum - due to high ionization energies - are shown as dashed grey arrows. 


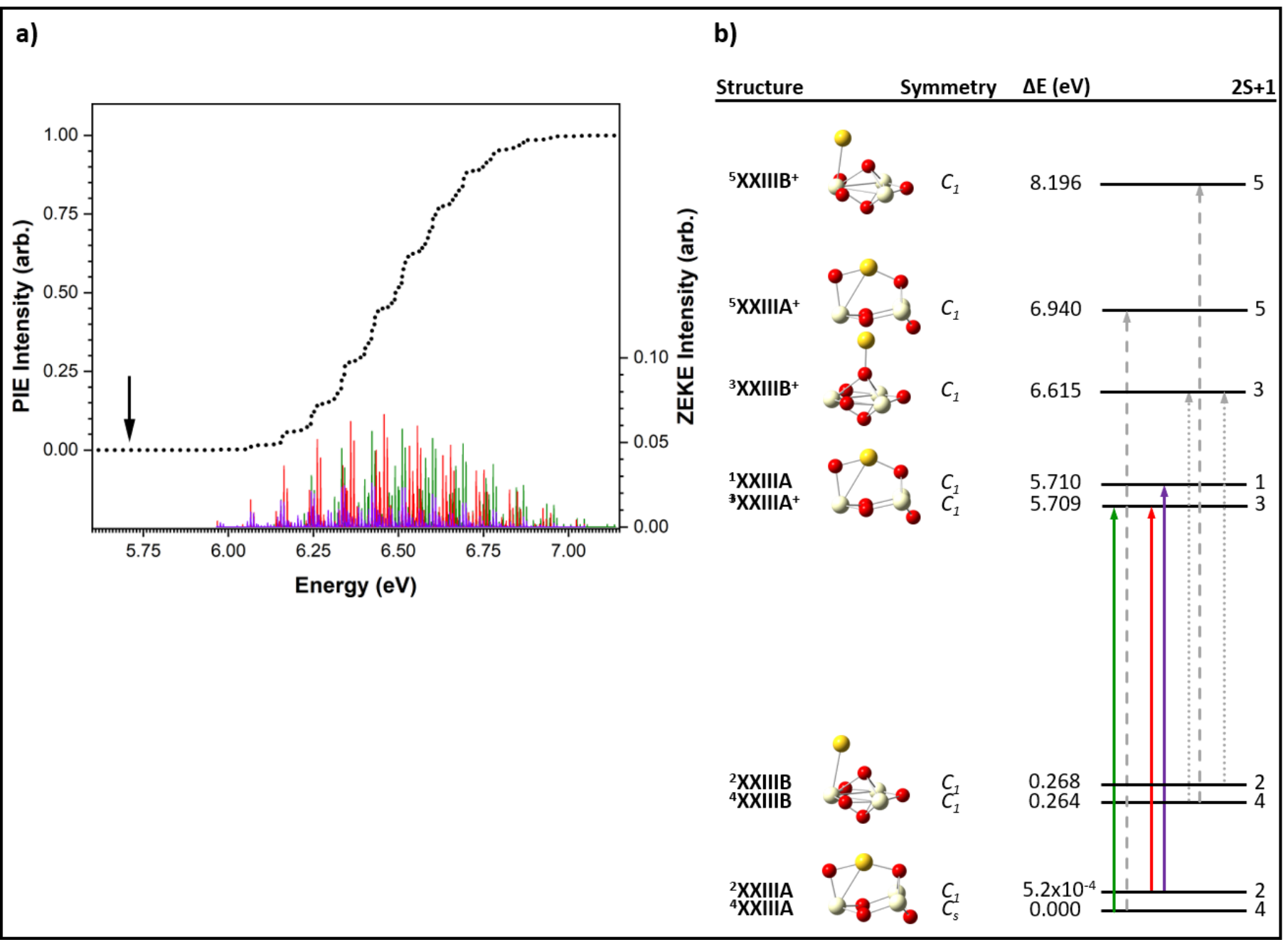

Figure S13: a). PIE spectrum for the $\mathrm{AuCe}_{3} \mathrm{O}_{5}$ cluster. The calculated PIE spectrum is shown as a dotted black line. Calculated ZEKE spectra for underlying ionization transitions are shown below the PIE spectra in green, red and violet. The downward arrow indicates the calculated adiabatic IE, the lowest energy origin transition. b). Calculated $\mathrm{AuCe}_{3} \mathrm{O}_{5}$ structures ( $\mathrm{Au}$ is yellow, $\mathrm{Ce}$ is white and $\mathrm{O}$ is red) and ionization processes. Ionization transitions are shown as coloured arrows which correspond to their respective ZEKE spectra. Ionization processes not considered to contribute to the PIE spectrum - due to high ionization energies and weak FC overlap - are shown as dashed grey arrows and dotted grey arrows, respectively. 


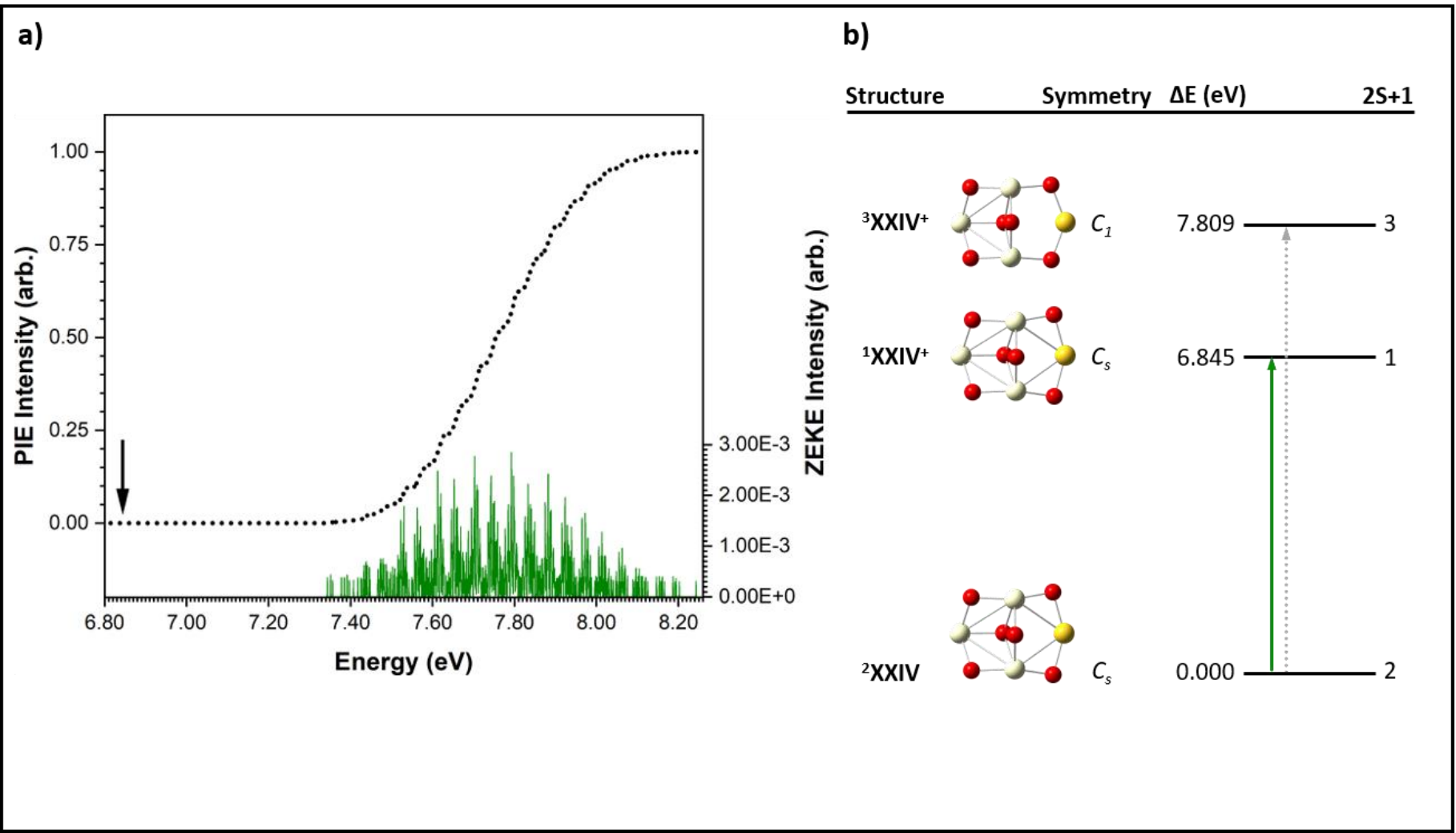

Figure S14: a). PIE spectrum for the $\mathrm{AuCe}_{3} \mathrm{O}_{6}$ cluster. The calculated PIE spectrum is shown as a dotted black line. The calculated ZEKE spectrum for the underlying ionization transition is shown below the PIE spectrum in green. The downward arrow indicates the calculated adiabatic IE, the lowest energy origin transition. b). Calculated $\mathrm{AuCe}_{3} \mathrm{O}_{6}$ structures ( $\mathrm{Au}$ is yellow, $\mathrm{Ce}$ is white and $\mathrm{O}$ is $\mathrm{red}$ ) and ionization processes. Ionization transitions are shown as coloured arrows which correspond to their respective ZEKE spectra. Ionization processes not considered to contribute to the PIE spectrum - due to weak FC overlap - are shown as dotted grey arrows. 


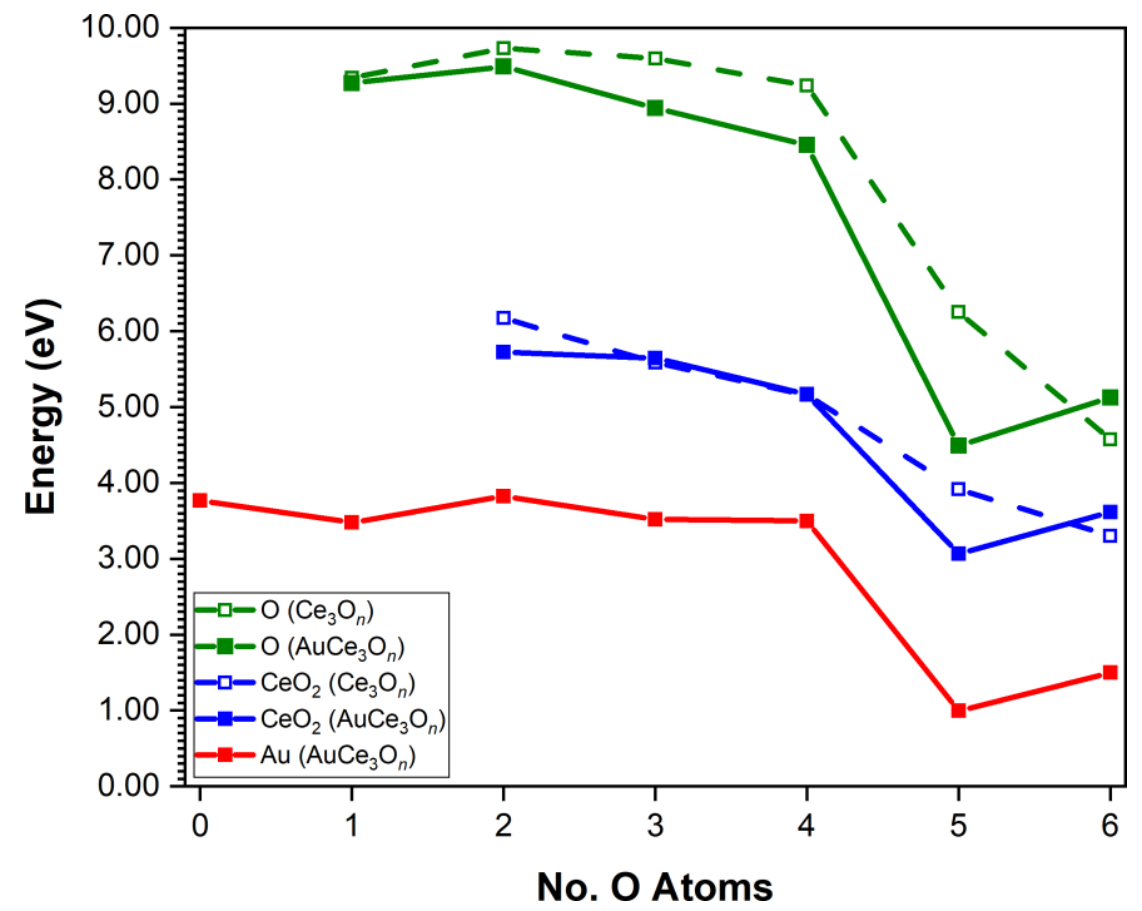

Figure S15: Calculated $\mathrm{Au}$ (red), $\mathrm{O}$ (green) and $\mathrm{CeO}_{2}$ (blue) bonding energies for neutral $\mathrm{Ce}_{3} \mathrm{O}_{n}$ (dashed line) and $\mathrm{AuCe}_{3} \mathrm{O}_{n}$ (solid line) clusters. 
$\mathrm{Ce}_{3}$

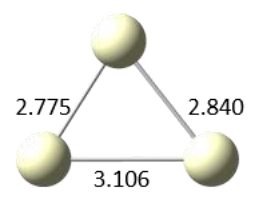

${ }^{7}$ VIA $\left(C_{s}\right)$

$0.000 \mathrm{eV}$

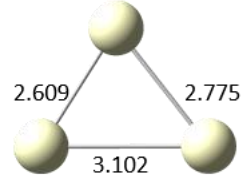

${ }^{5} \mathrm{VIA}\left(C_{s}\right)$

$+0.087 \mathrm{eV}$

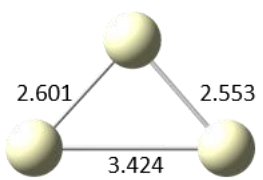

${ }^{3} \mathrm{VIB}\left(C_{s}\right)$

$+0.183 \mathrm{eV}$

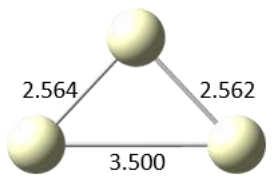

${ }^{5} \mathrm{VIB}\left(C_{s}\right)$

$+0.195 \mathrm{eV}$

\section{$\mathrm{Ce}_{3}{ }^{+}$}

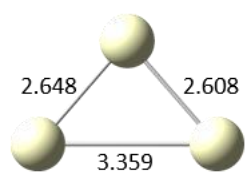

${ }^{6} \mathrm{VIB}^{+}\left(C_{s}\right)$

$+4.482 \mathrm{eV}$

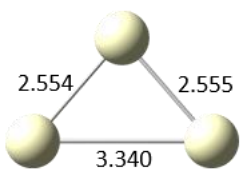

${ }^{2} \mathrm{VIB}^{+}\left(C_{s}\right)$

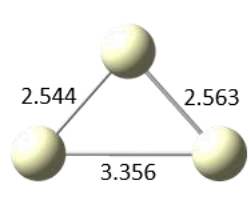

${ }^{4} \mathrm{VIB}^{+}\left(C_{s}\right)$

$+4.864 \mathrm{eV}$

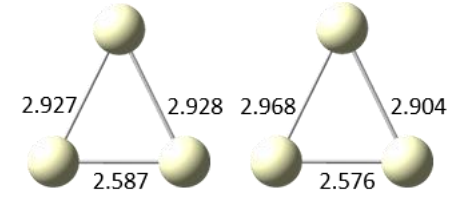

${ }^{8} \mathrm{VIA}^{+}\left(C_{s}\right) \quad{ }^{6} \mathrm{VIA}^{+}\left(C_{s}\right)$

$+4.966 \mathrm{eV} \quad+5.103 \mathrm{eV}$

Figure S16: Calculated Ceз neutral and cationic structures. Bond lengths are presented in $\AA$. Point groups are shown in brackets. Energies are shown relative to the lowest energy neutral structure. 
$\mathrm{Ce}_{3} \mathrm{O}$

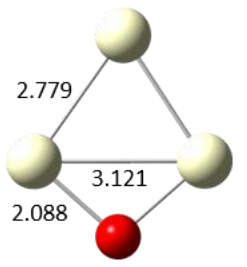

$\angle \mathrm{O}-\mathrm{Ce}-\mathrm{Ce}-\mathrm{Ce}=179.9^{\circ}$

${ }^{5} \mathrm{VIIA}\left(C_{s}\right)$

$0.000 \mathrm{eV}$

$\mathrm{Ce}_{3} \mathrm{O}^{+}$

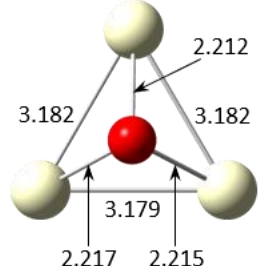

${ }^{6} \mathrm{VIIB}^{+}\left(C_{1}\right)$

$+4.698 \mathrm{eV}$

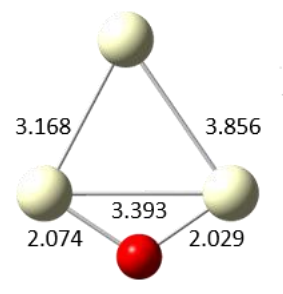

$\angle \mathrm{O}-\mathrm{Ce}-\mathrm{Ce}-\mathrm{Ce}=179.9^{\circ}$

${ }^{4} \mathrm{VIIA}^{+}\left(C_{1}\right)$

$+4.833 \mathrm{eV}$

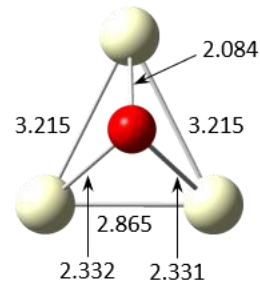

${ }^{7} \mathrm{VIIB}\left(C_{1}\right)$

$+0.209 \mathrm{eV}$
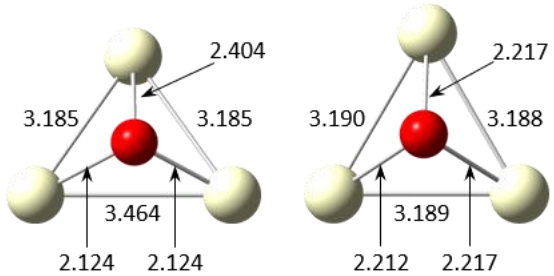

${ }^{5} \mathrm{VIIB}\left(C_{1}\right)$

$+0.264 \mathrm{eV}$

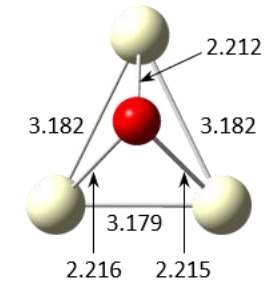

$2.212 \quad 2.217$

${ }^{4} \mathrm{VIIB}^{+}\left(C_{1}\right)$

$+4.795 \mathrm{eV}$

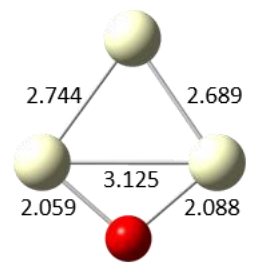

$\angle \mathrm{O}-\mathrm{Ce}-\mathrm{Ce}-\mathrm{Ce}=179.9^{\circ}$

${ }^{6} \mathrm{VIIA}^{+}\left(C_{1}\right)$

$+5.049 \mathrm{eV}$

Figure S17: Calculated $\mathrm{Ce}_{3} \mathrm{O}$ neutral and cationic structures. Bond lengths are presented in $\AA$. Point groups are shown in brackets. Energies are shown relative to the lowest energy neutral structure. 
$\mathrm{Ce}_{3} \mathrm{O}_{2}$

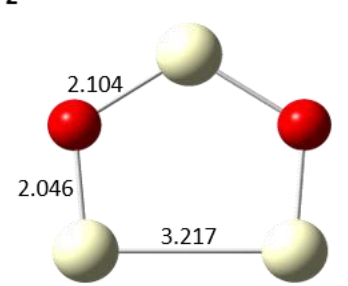

${ }^{5}$ VIIIA $\left(C_{2 v}\right)$

$0.000 \mathrm{eV}$

$\mathrm{Ce}_{3} \mathrm{O}_{2}{ }^{+}$

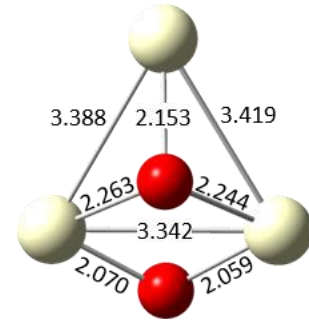

${ }^{6} \mathrm{VIIIB}^{+}\left(C_{1}\right)$

$+4.387 \mathrm{eV}$

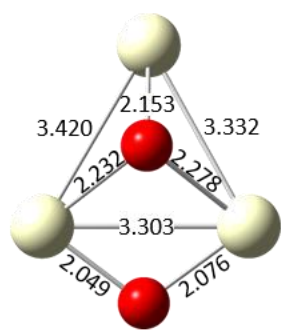

${ }^{4} \mathrm{VIIIB}^{+}\left(C_{1}\right)$

$+4.503 \mathrm{eV}$

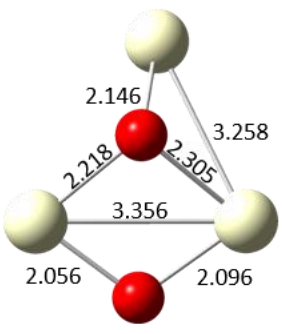

${ }^{3}$ VIIIB $\left(C_{1}\right)$

$+0.047 \mathrm{eV}$

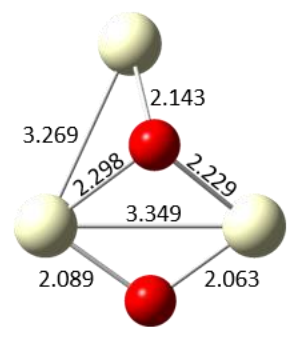

${ }^{5} \mathrm{VIIIB}\left(C_{1}\right)$

$+0.051 \mathrm{eV}$

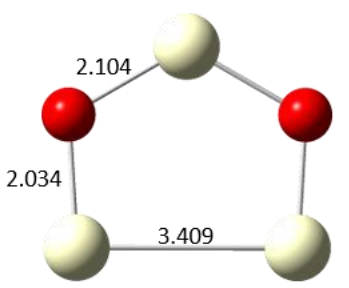

${ }^{6} \mathrm{VIIIA}^{+}\left(C_{s}\right)$

$+4.498 \mathrm{eV}$

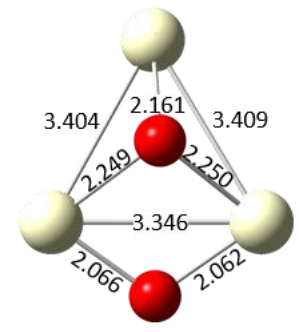

${ }^{2} \mathrm{VIIIB}^{+}\left(C_{1}\right)$

$+4.520 \mathrm{eV}$

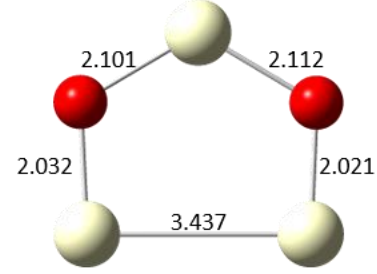

${ }^{4} \mathrm{VIIIA}^{+}\left(C_{1}\right)$

$+4.553 \mathrm{eV}$

Figure S18: Calculated $\mathrm{Ce}_{3} \mathrm{O}_{2}$ neutral and cationic structures. Bond lengths are presented in $\AA$. Point groups are shown in brackets. Energies are shown relative to the lowest energy neutral structure. 
$\mathrm{Ce}_{3} \mathrm{O}_{3}$

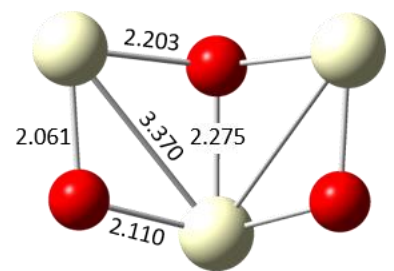

$\angle \mathrm{Ce}-\mathrm{O}-\mathrm{Ce}=118.4^{\circ}$

$5 \mathrm{IX}\left(C_{s}\right)$

$0.000 \mathrm{eV}$

$\mathrm{Ce}_{3} \mathrm{O}_{3}{ }^{+}$

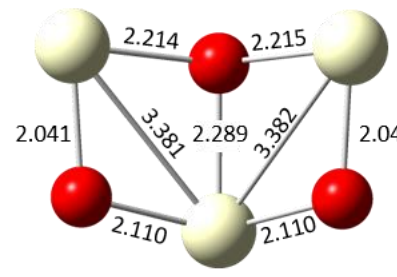

$\angle \mathrm{Ce}-\mathrm{O}-\mathrm{Ce}=104.9^{\circ}$

${ }^{2} \mathrm{XX}^{+}\left(C_{1}\right)$

$+4.214 \mathrm{eV}$

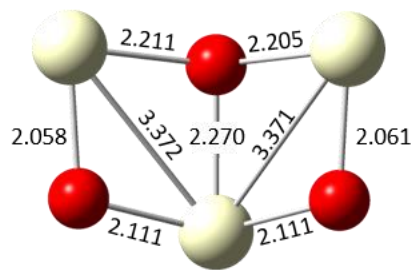

$\angle \mathrm{Ce}-\mathrm{O}-\mathrm{Ce}=117.8^{\circ}$

${ }^{3} \mathrm{IX}\left(C_{1}\right)$

$+0.016 \mathrm{eV}$

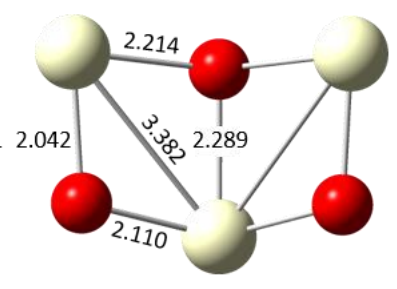

$\angle \mathrm{Ce}-\mathrm{O}-\mathrm{Ce}=104.8^{\circ}$

${ }^{4} \mathrm{IX}^{+}\left(C_{s}\right)$

$+4.216 \mathrm{eV}$

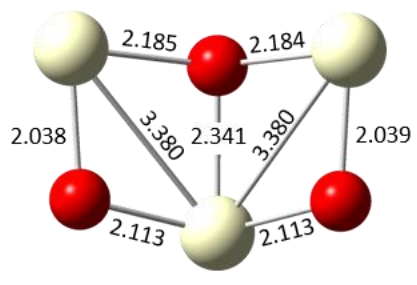

$\angle \mathrm{Ce}-\mathrm{O}-\mathrm{Ce}=132.5^{\circ}$

${ }^{6} \mathrm{IX}^{+}\left(C_{1}\right)$

$+4.600 \mathrm{eV}$

Figure S19: Calculated $\mathrm{Ce}_{3} \mathrm{O}_{3}$ neutral and cationic structures. Bond lengths are presented in $\AA$. Point groups are shown in brackets. Energies are shown relative to the lowest energy neutral structure. 

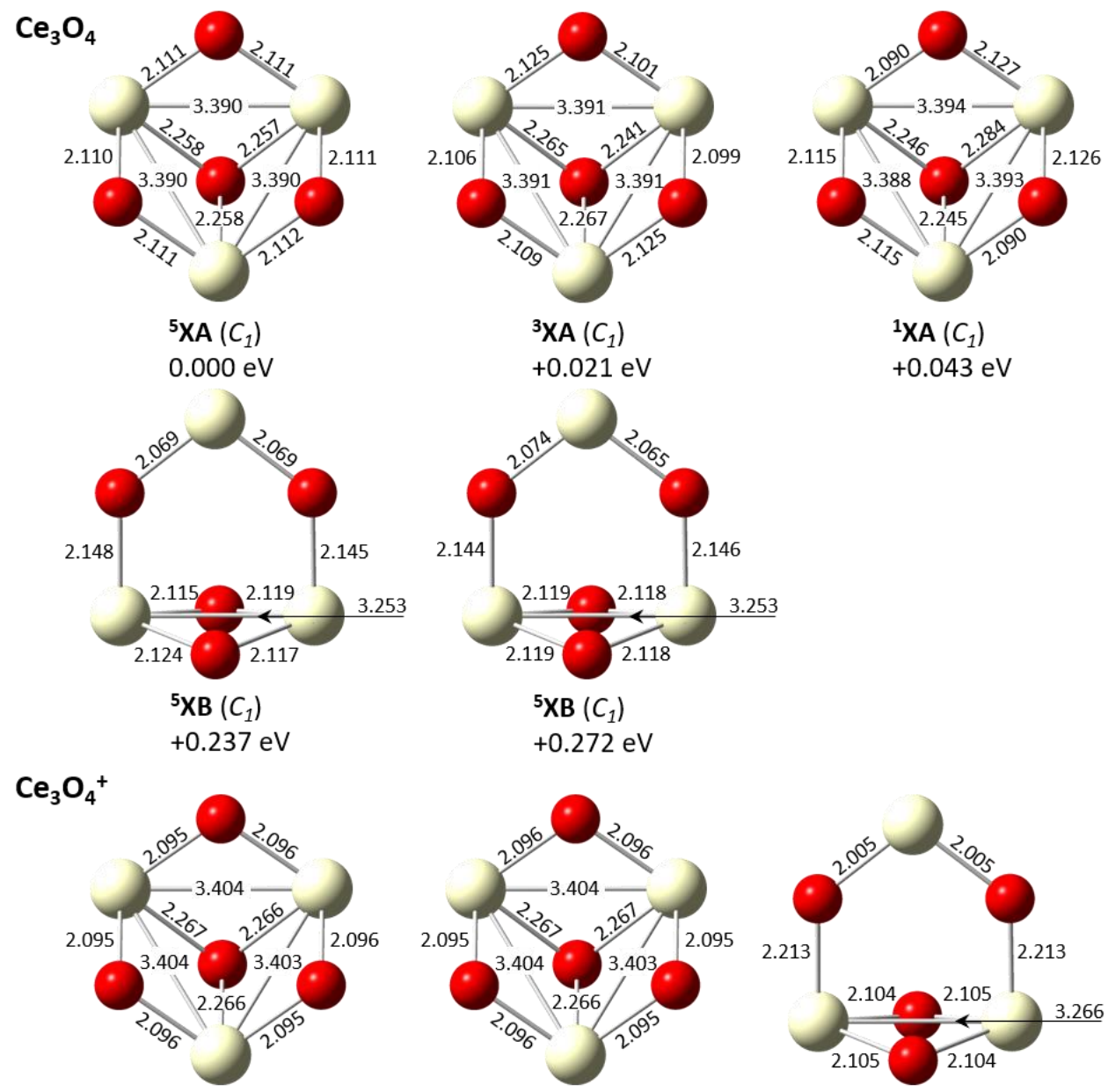

${ }^{2} \mathrm{XA}^{+}\left(C_{1}\right)$

$+3.899 \mathrm{eV}$
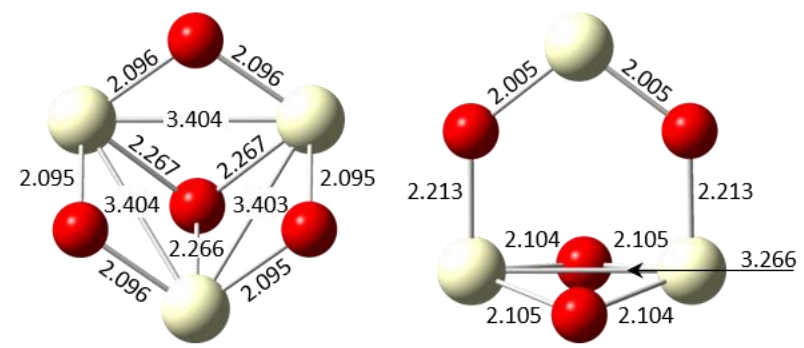

${ }^{4} \mathrm{XA}^{+}\left(C_{1}\right)$

${ }^{4} \mathrm{XB}^{+}\left(C_{1}\right)$

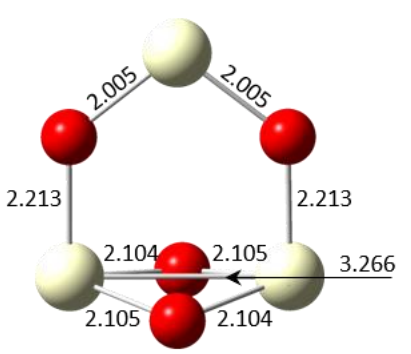

${ }^{2} \mathrm{XB}^{+}\left(C_{1}\right)$

$+4.512 \mathrm{eV}$
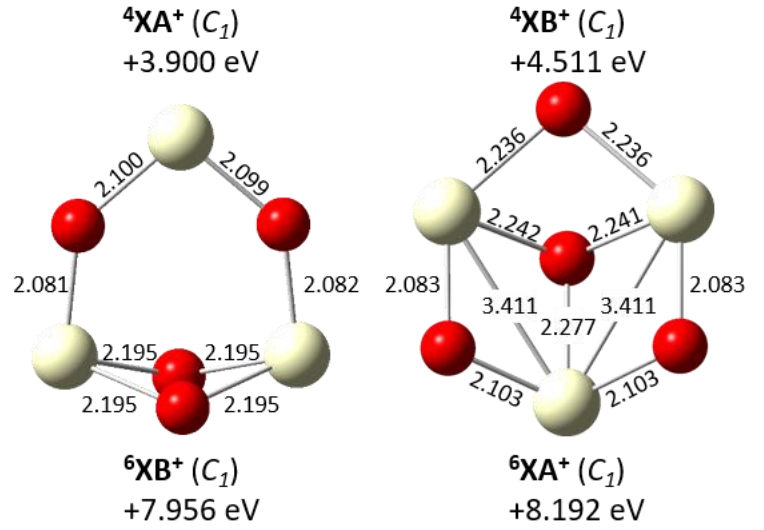

Figure S20: Calculated $\mathrm{Ce}_{3} \mathrm{O}_{4}$ neutral and cationic structures. Bond lengths are presented in $\AA$. Point groups are shown in brackets. Energies are shown relative to the lowest energy neutral structure. 
$\mathrm{Ce}_{3} \mathrm{O}_{5}$

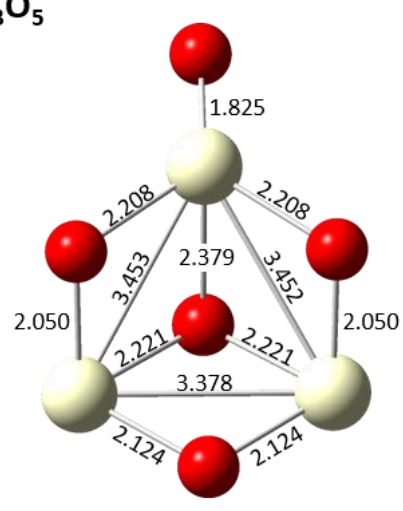

${ }^{3}$ XIA $\left(C_{1}\right)$

$0.000 \mathrm{eV}$

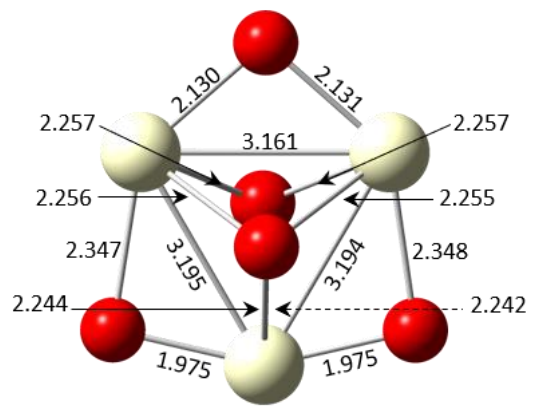

${ }^{3} \mathrm{XIB}\left(C_{1}\right)$

$\mathrm{Ce}_{3} \mathrm{O}_{5}{ }^{+}$

$+0.121 \mathrm{eV}$

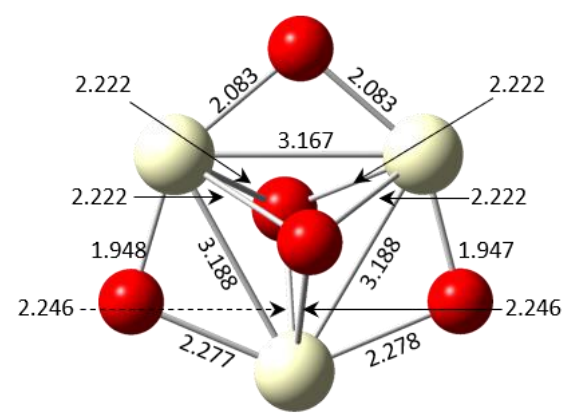

${ }^{2} \mathrm{XIB}^{+}\left(C_{1}\right)$

$+6.142 \mathrm{eV}$

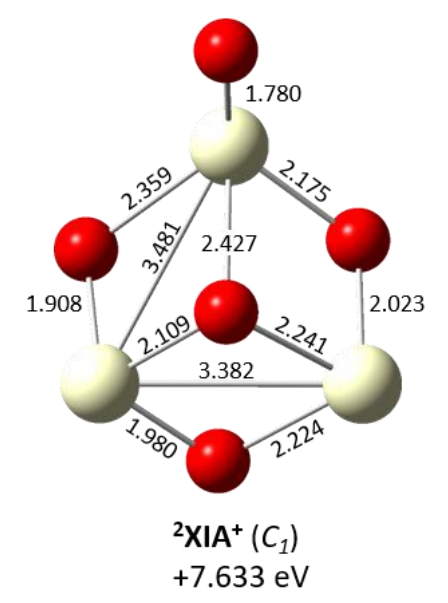

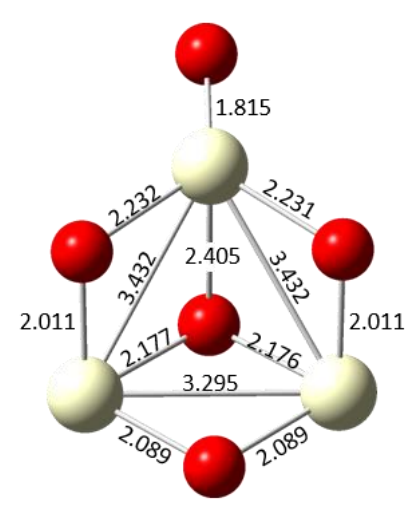

${ }^{1} \mathrm{XIA}\left(C_{1}\right)$

$+0.120 \mathrm{eV}$

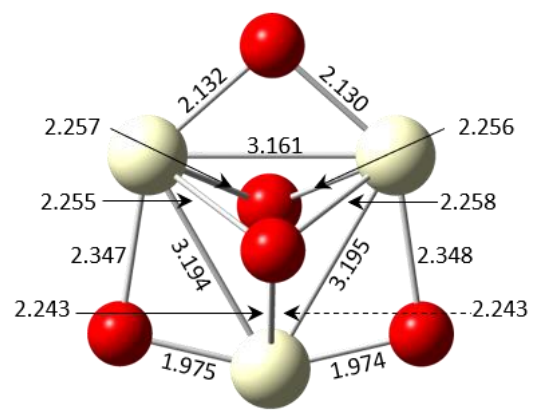

${ }^{1}$ XIB $\left(C_{1}\right)$

$+0.149 \mathrm{eV}$

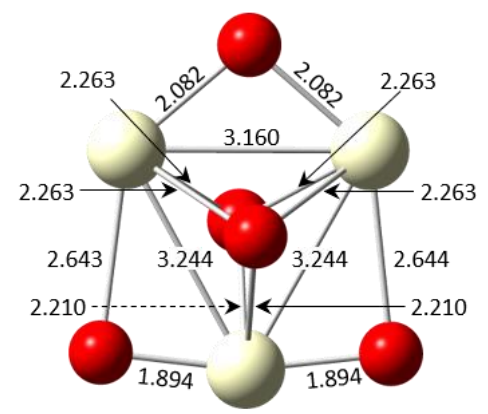

${ }^{4} \mathrm{XIB}^{+}\left(C_{1}\right)$

$6.376 \mathrm{eV}$

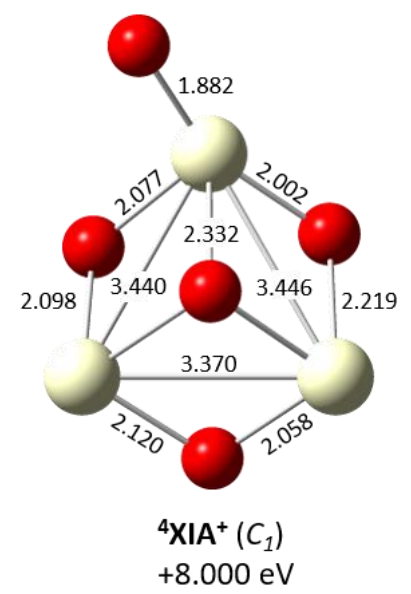

Figure S21: Calculated $\mathrm{Ce}_{3} \mathrm{O}_{5}$ neutral and cationic structures. Bond lengths are presented in $\AA$. Point groups are shown in brackets. Energies are shown relative to the lowest energy neutral structure. 
$\mathrm{Ce}_{3} \mathrm{O}_{6}$

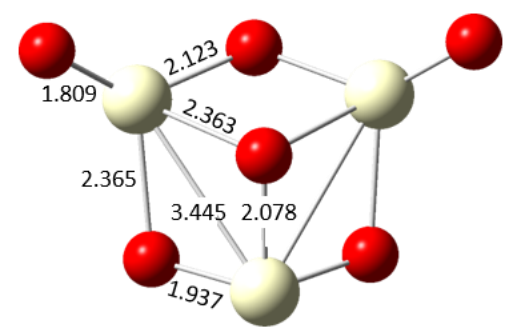

${ }^{1} \mathrm{XII}\left(C_{s}\right)$

$0.000 \mathrm{eV}$

$\mathrm{Ce}_{3} \mathrm{O}_{6}{ }^{+}$

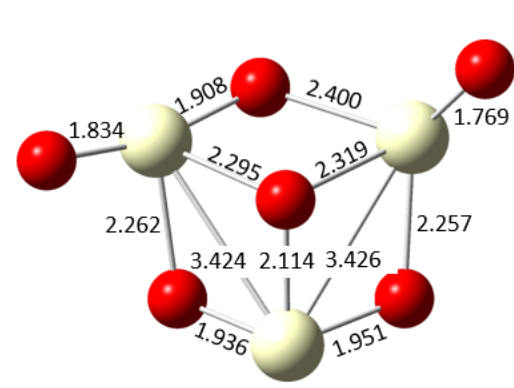

${ }^{2} \mathrm{XII}^{+}\left(C_{1}\right)$

$+8.482 \mathrm{eV}$

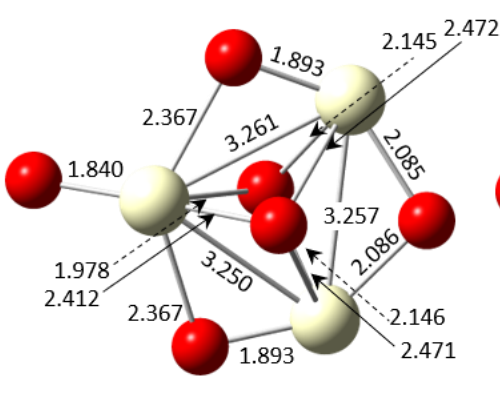

${ }^{2} \mathrm{XIIA}^{+}\left(C_{1}\right)$

$+8.640 \mathrm{eV}$

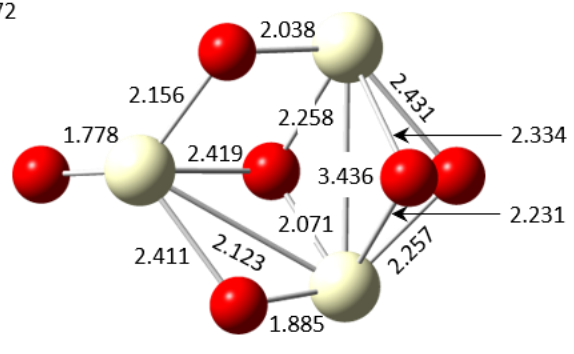

${ }^{2} \operatorname{XIIB}^{+}\left(C_{1}\right)$

$+8.764 \mathrm{eV}$

Figure S22: Calculated $\mathrm{Ce}_{3} \mathrm{O}_{6}$ neutral and cationic structures. Bond lengths are presented in $\AA$. Point groups are shown in brackets. Energies are shown relative to the lowest energy neutral structure.

\section{$\mathrm{AuCe}_{3}$}

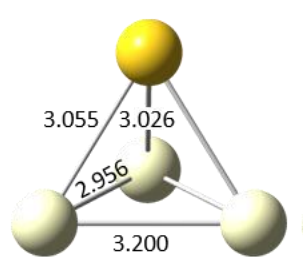

${ }^{8} \mathrm{XVIII}\left(C_{s}\right)$

$0.000 \mathrm{eV}$

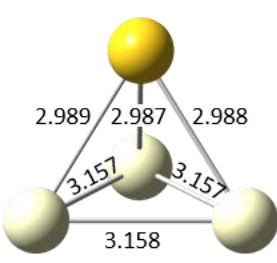

${ }^{10} \mathrm{XVIII}\left(C_{1}\right)$

$+0.052 \mathrm{eV}$

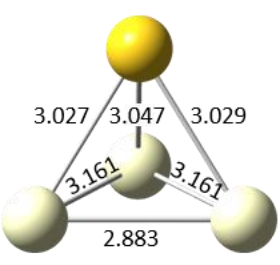

${ }^{6} \mathrm{XVIII}\left(C_{1}\right)$

$+0.128 \mathrm{eV}$

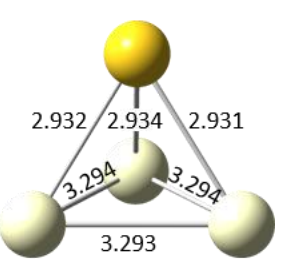

${ }^{4} \mathrm{XVIII}\left(C_{1}\right)$

$+0.393 \mathrm{eV}$

\section{$\mathrm{AuCe}_{3}{ }^{+}$}

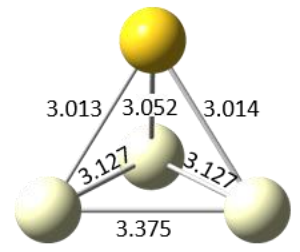

${ }^{9} \mathrm{XVIII}{ }^{+}\left(C_{1}\right)$

$+4.937 \mathrm{eV}$

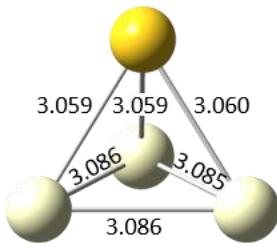

${ }^{7} \mathrm{XVIII+}\left(C_{1}\right)$

$+4.983 \mathrm{eV}$

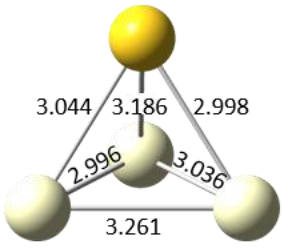

${ }^{3} \mathrm{XVIII}+\left(C_{1}\right)$

$+5.110 \mathrm{eV}$

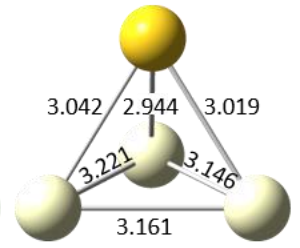

${ }^{5} \mathrm{XVIII}^{+}\left(C_{1}\right)$

$+5.222 \mathrm{eV}$

Figure S23: Calculated $\mathrm{AuCe}_{3}$ neutral and cationic structures. Bond lengths are presented in $\AA$. Point groups are shown in brackets. Energies are shown relative to the lowest energy neutral structure. 


\section{$\mathrm{AuCe}_{3} \mathrm{O}$}
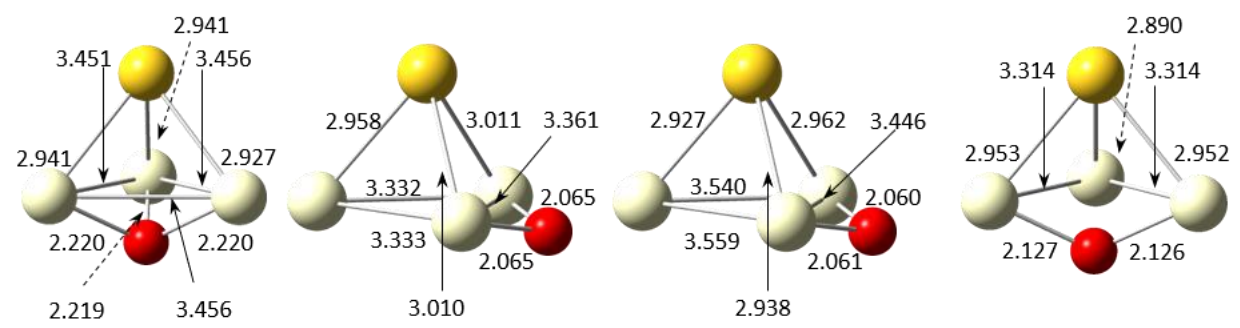

${ }^{2} \mathrm{XIXA}\left(C_{1}\right)$
$0.000 \mathrm{eV}$

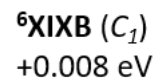

${ }^{4}$ XIXB $\left(C_{1}\right)$
$+0.013 \mathrm{eV}$

${ }^{6} \mathrm{XIXA}\left(C_{1}\right)$ $+0.023 \mathrm{eV}$

\section{$\mathrm{AuCe}_{3} \mathrm{O}^{+}$}
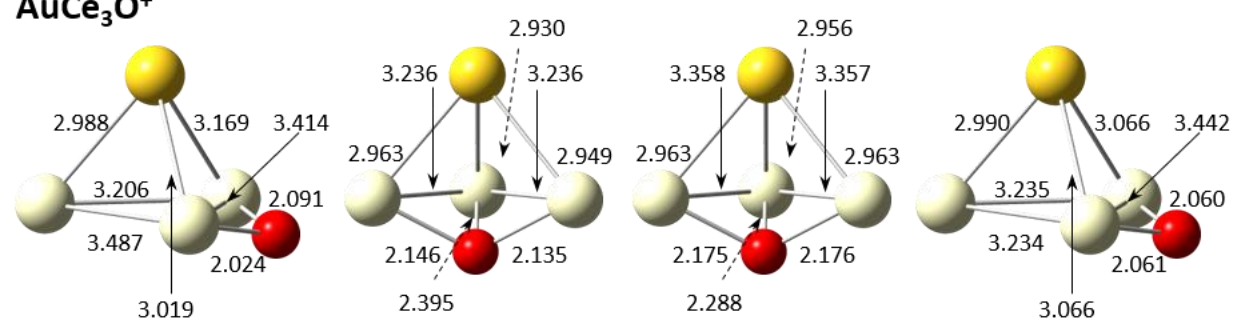

\section{${ }^{7} \mathrm{XIXB}^{+}\left(C_{1}\right)$}

$+4.600 \mathrm{eV}$ 2.959

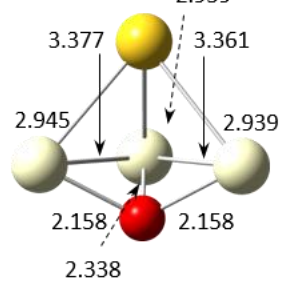

${ }^{7} \mathrm{XIXA}^{+}\left(C_{1}\right)$ $+4.748 \mathrm{eV}$

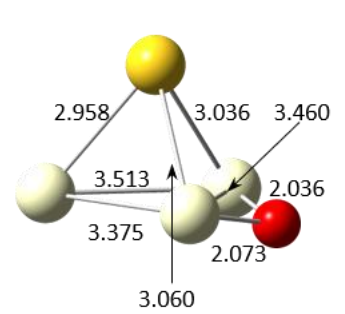

${ }^{5} \mathrm{XIXA}^{+}\left(C_{1}\right)$

$$
+4.812 \mathrm{eV}
$$

${ }^{5} \mathrm{XIXB}^{+}\left(C_{1}\right)$ $+4.831 \mathrm{eV}$

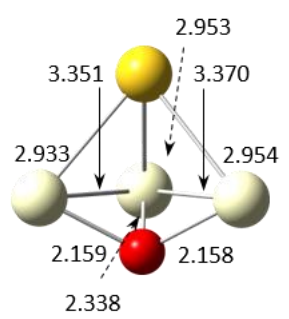

$$
\begin{array}{lll}
{ }^{1} \mathrm{XIXA}^{+}\left(C_{1}\right) & { }^{3} \mathrm{XIXB}^{+}\left(C_{1}\right) & { }^{3} \mathrm{XIXA}^{+}\left(C_{1}\right) \\
+4.844 \mathrm{eV} & +4.849 \mathrm{eV} & +4.876 \mathrm{eV}
\end{array}
$$

Figure S24: Calculated $\mathrm{AuCe}_{3} \mathrm{O}$ neutral and cationic structures. Bond lengths are presented in $\AA$. Point groups are shown in brackets. Energies are shown relative to the lowest energy neutral structure. 
$\mathrm{AuCe}_{3} \mathrm{O}_{2}$

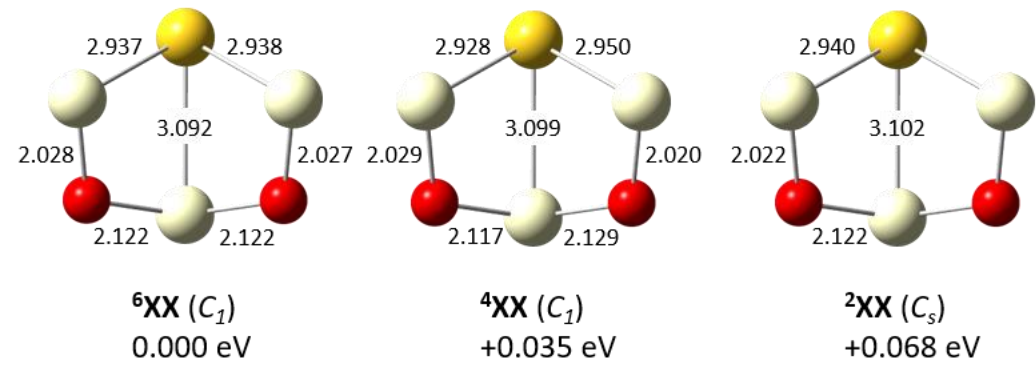

$\mathrm{AuCe}_{3} \mathrm{O}_{2}^{+}$

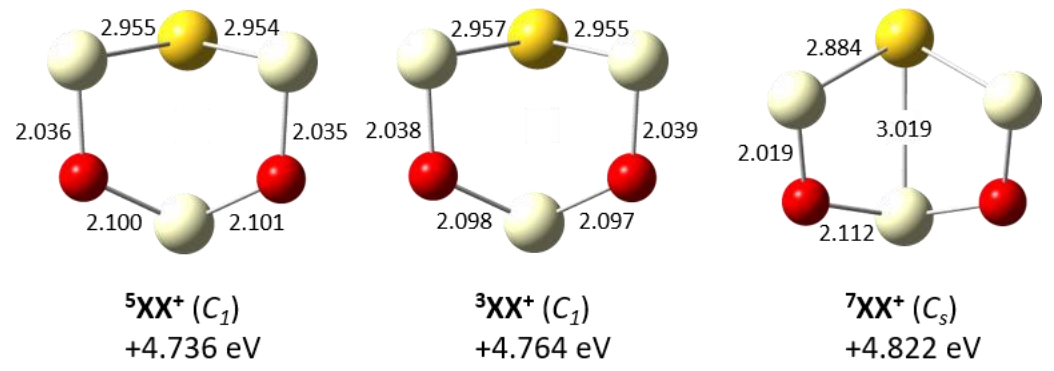

Figure S25: Calculated $\mathrm{AuCe}_{3} \mathrm{O}_{2}$ neutral and cationic structures. Bond lengths are presented in $\AA$. Point groups are shown in brackets. Energies are shown relative to the lowest energy neutral structure. 


\section{$\mathrm{AuCe}_{3} \mathrm{O}_{3}$}

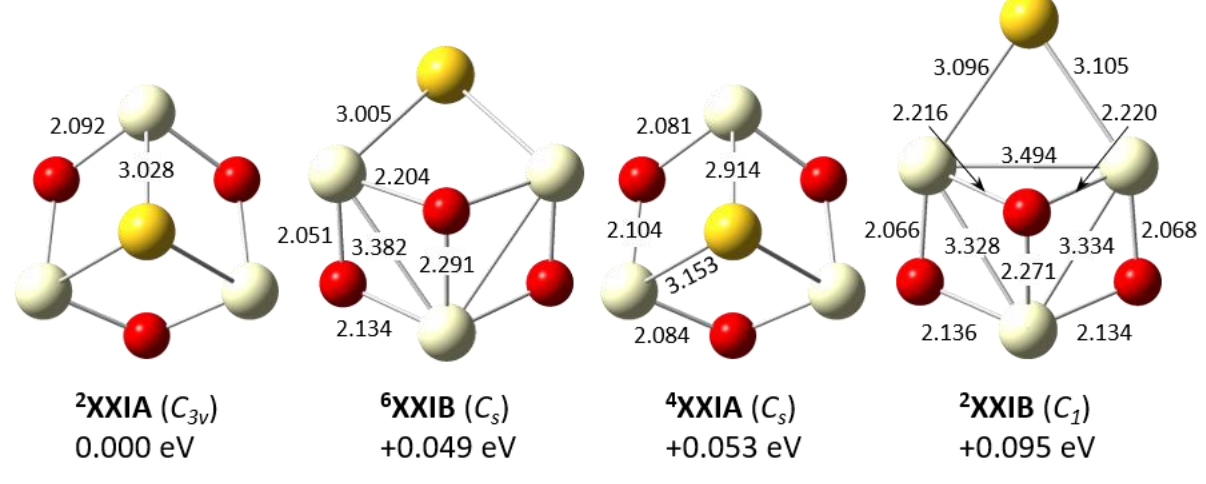

\section{$\mathrm{AuCe}_{3} \mathrm{O}_{3}{ }^{+}$}

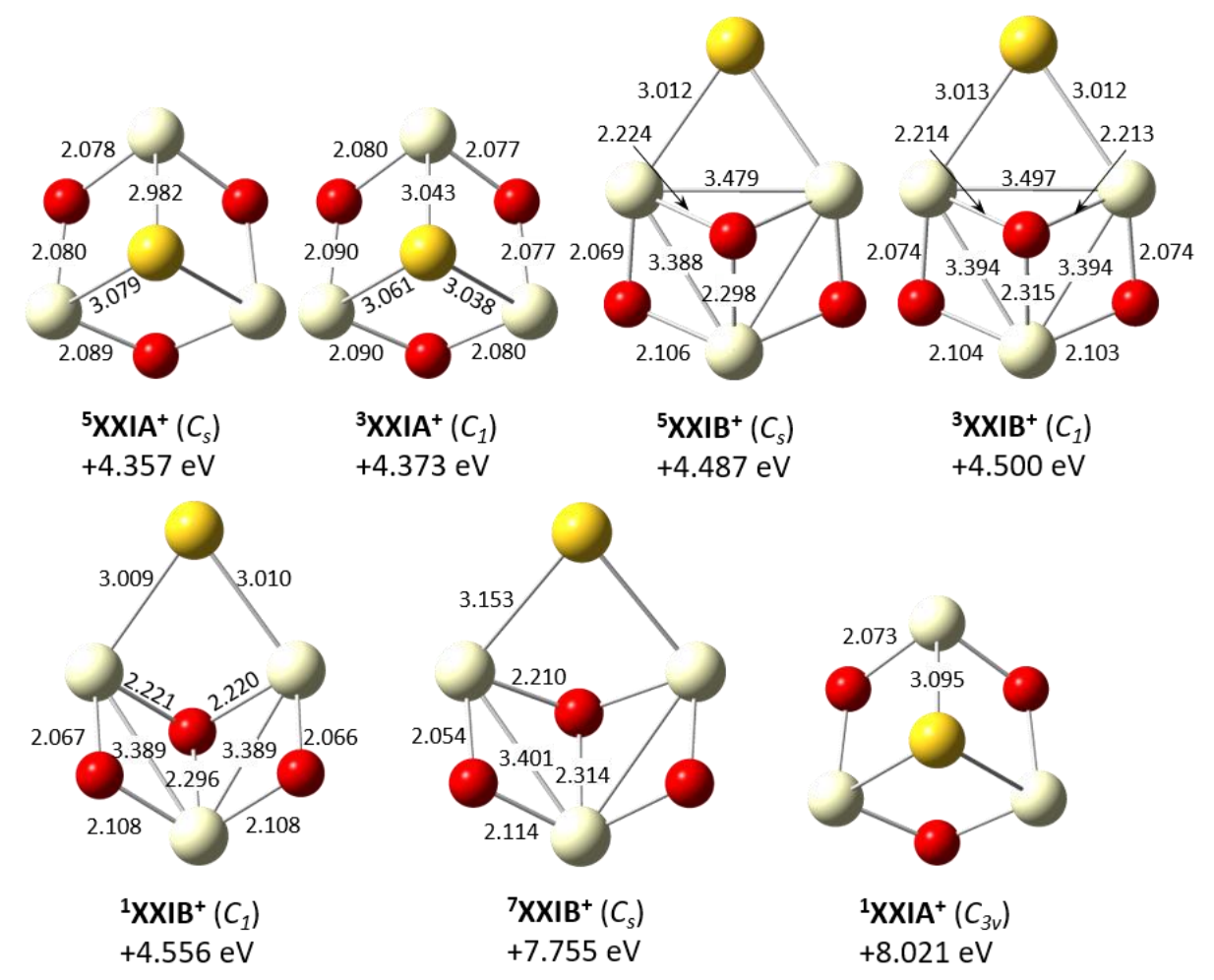

Figure S26: Calculated $\mathrm{AuCe}_{3} \mathrm{O}_{3}$ neutral and cationic structures. Bond lengths are presented in $\AA$. Point groups are shown in brackets. Energies are shown relative to the lowest energy neutral structure. 
$\mathrm{AuCe}_{3} \mathrm{O}_{4}$

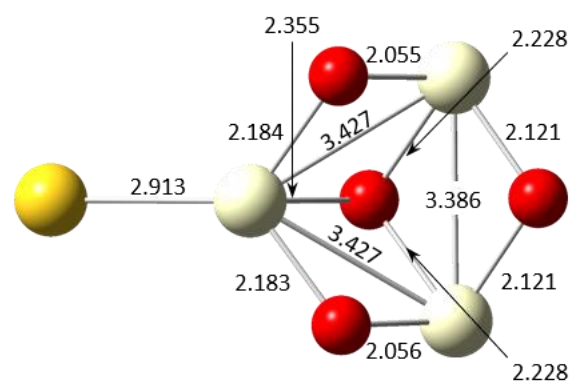

${ }^{2}$ XXII $\left(C_{1}\right)$

$0.000 \mathrm{eV}$

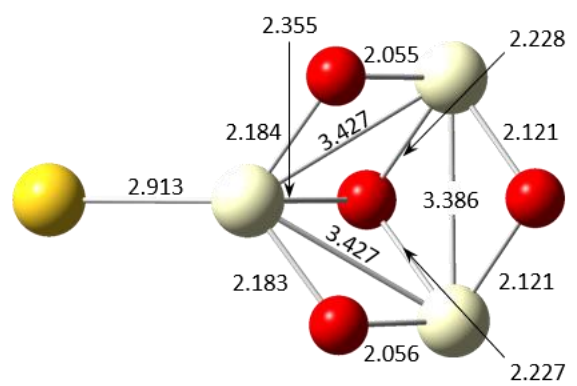

${ }^{4}$ XXII $\left(C_{1}\right)$

$+0.003 \mathrm{eV}$

$\mathrm{AuCe}_{3} \mathrm{O}_{4}{ }^{+}$

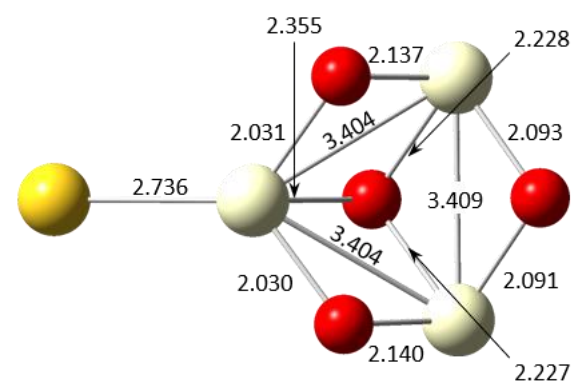

${ }^{3} \mathrm{XXII}^{+}\left(C_{1}\right)$

$+6.369 \mathrm{eV}$

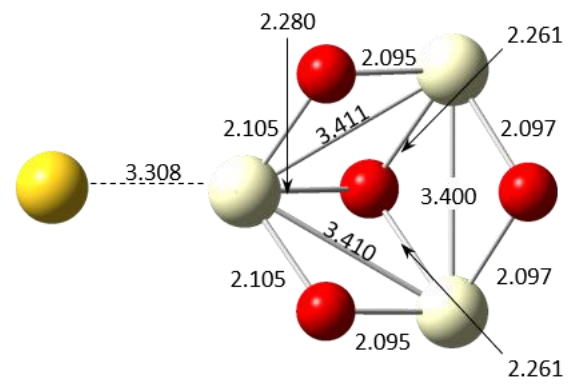

${ }^{5} \mathrm{XXII}^{+}\left(C_{1}\right)$

$+7.103 \mathrm{eV}$

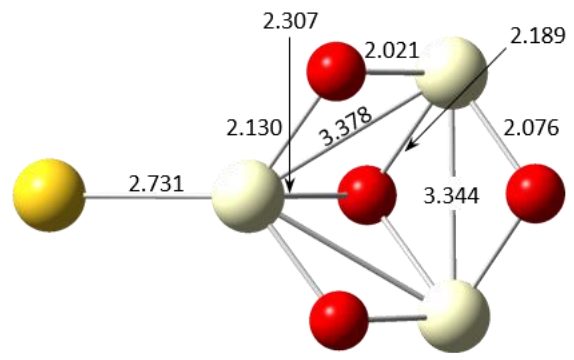

${ }^{1} \mathrm{XXII}^{+}\left(C_{s}\right)$

$+8.586 \mathrm{eV}$

Figure S27: Calculated $\mathrm{AuCe}_{3} \mathrm{O}_{4}$ neutral and cationic structures. Bond lengths are presented in $\AA$. Point groups are shown in brackets. Energies are shown relative to the lowest energy neutral structure. 
$\mathrm{AuCe}_{3} \mathrm{O}_{5}$

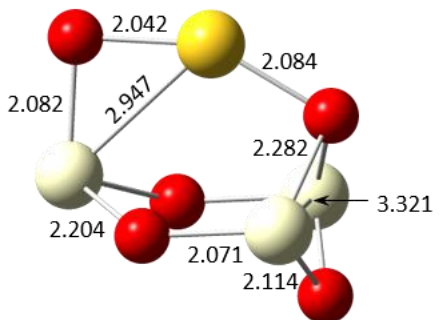

${ }^{4}$ XXIIIA $\left(C_{s}\right)$

$0.000 \mathrm{eV}$

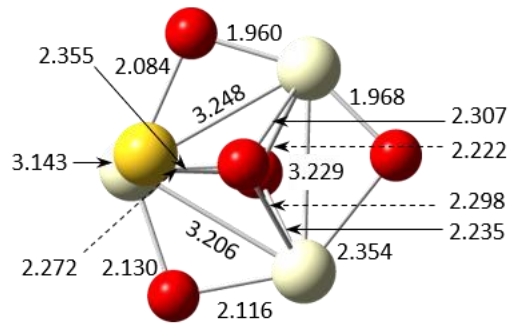

${ }^{4} \mathrm{XXIIIB}\left(C_{1}\right)$

$+0.264 \mathrm{eV}$

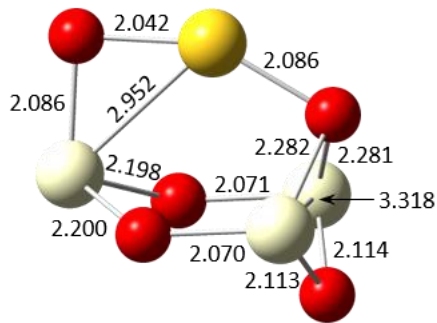

${ }^{2} \mathrm{XXIIIA}\left(C_{1}\right)$

$+5.2 \times 10^{-4} \mathrm{eV}$

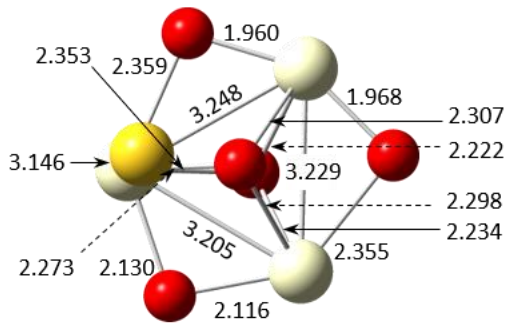

${ }^{2} \mathrm{XXIIIB}\left(C_{1}\right)$

$+0.268 \mathrm{eV}$
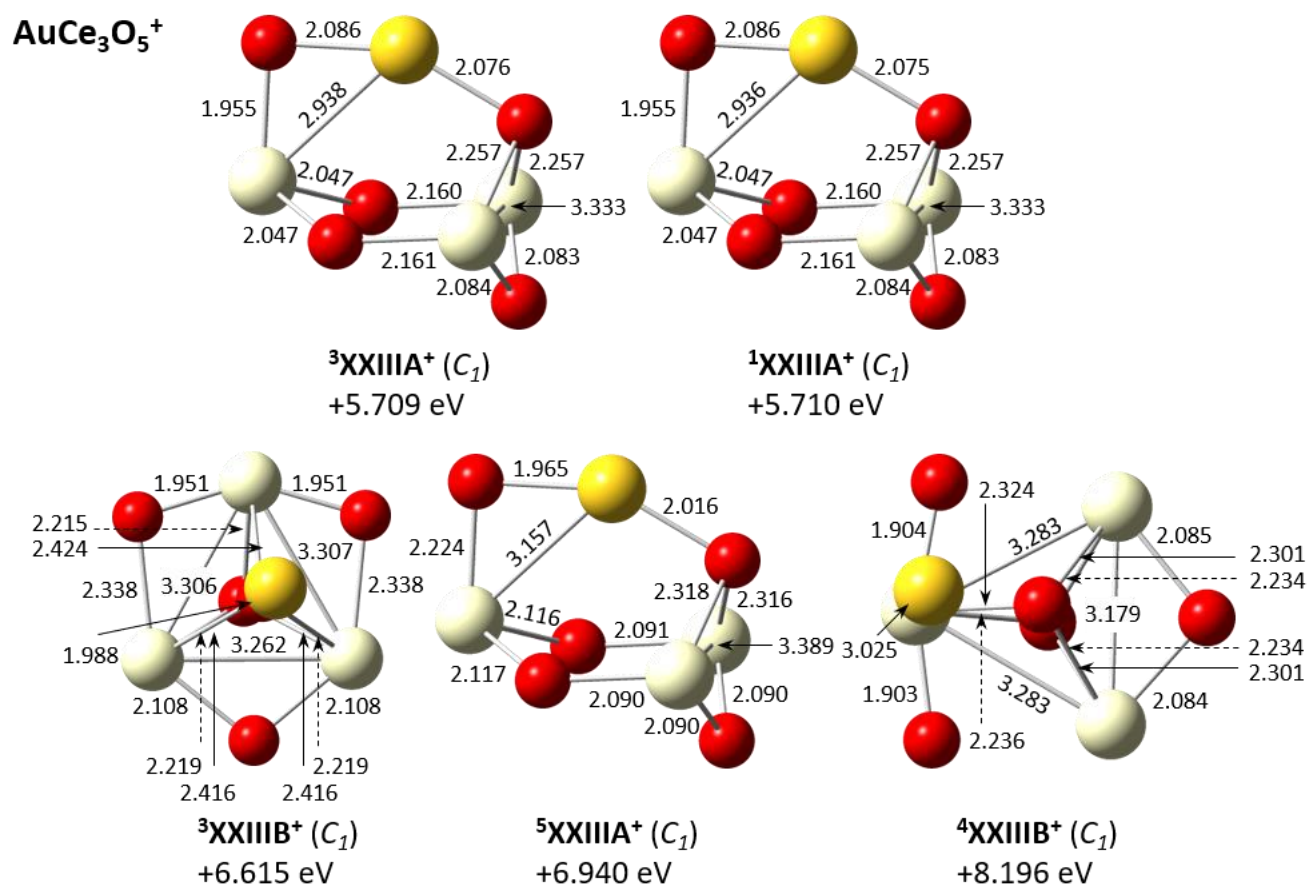

Figure S28: Calculated $\mathrm{AuCe}_{3} \mathrm{O}_{5}$ neutral and cationic structures. Bond lengths are presented in $\AA$. Point groups are shown in brackets. Energies are shown relative to the lowest energy neutral structure. 


\section{$\mathrm{AuCe}_{3} \mathrm{O}_{6}$}
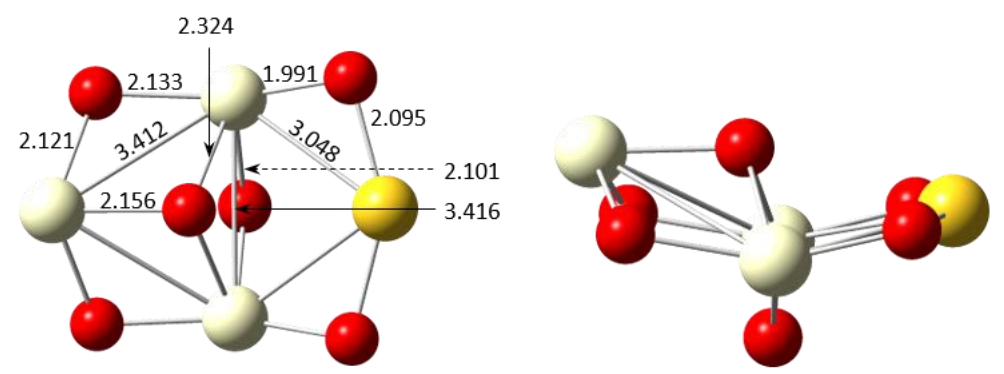

${ }^{2} \operatorname{XXIV}\left(C_{s}\right)$

$0.000 \mathrm{eV}$

\section{$\mathrm{AuCe}_{3} \mathrm{O}_{6}^{+}$}

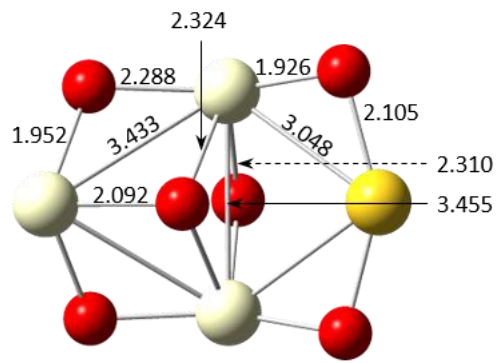

${ }^{1} \mathbf{X X I V}^{+}\left(C_{s}\right)$

$+6.845 \mathrm{eV}$

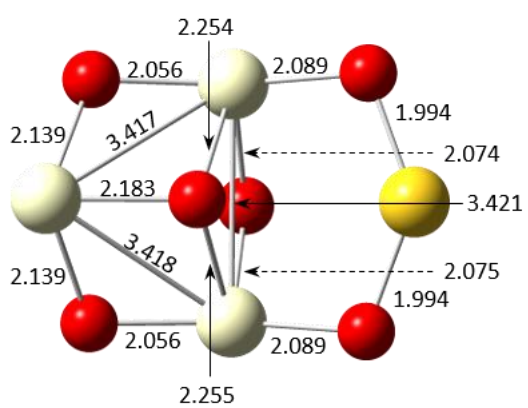

${ }^{3} \mathrm{XXIV}^{+}\left(C_{1}\right)$

$+7.809 \mathrm{eV}$

Figure S29: Calculated $\mathrm{AuCe}_{3} \mathrm{O}_{6}$ neutral and cationic structures. Bond lengths are presented in $\AA$. Point groups are shown in brackets. Energies are shown relative to the lowest energy neutral structure. 